\title{
Analysis of Seepage Characteristics of a Foundation Pit with Horizontal Waterproof Curtain in Highly Permeable Strata
}

\author{
Chenghua Shi ${ }^{1}\left(\mathbb{D}\right.$, Xiaohe Sun $^{1, *}$, Shengli Liu ${ }^{2}$, Chengyong Cao ${ }^{3, *} \mathbb{C}$, Linghui Liu ${ }^{1} \oplus$ and Mingfeng Lei ${ }^{1}$ \\ 1 School of Civil Engineering, Central South University, Changsha 410075, China; csusch@163.com (C.S.); \\ liulinghui888@163.com (L.L.); mingfenglei@aliyun.com (M.L.) \\ 2 Guangzhou Metro Design \& Research Institute Co., Ltd., Guangzhou 510010, China; lius1101@163.com \\ 3 College of Civil and Transportation Engineering, Shenzhen University, Shenzhen 518060, China \\ * Correspondence: csusxh@163.com (X.S.); chengyongcao@163.com (C.C.)
}

Citation: Shi, C.; Sun, X.; Liu, S.; Cao,

C.; Liu, L.; Lei, M. Analysis of

Seepage Characteristics of a

Foundation Pit with Horizontal

Waterproof Curtain in Highly

Permeable Strata. Water 2021, 13, 1303.

https://doi.org/10.3390/w13091303

Academic Editor: Adriana

Bruggeman

Received: 30 March 2021

Accepted: 1 May 2021

Published: 6 May 2021

Publisher's Note: MDPI stays neutral with regard to jurisdictional claims in published maps and institutional affiliations.

Copyright: (C) 2021 by the authors. Licensee MDPI, Basel, Switzerland. This article is an open access article distributed under the terms and conditions of the Creative Commons Attribution (CC BY) license (https:// creativecommons.org/licenses/by/ $4.0 /)$.

\begin{abstract}
At present, jet-grouted horizontal waterproof curtain reinforcement has become an essential method for deep foundation pit groundwater control. However, there is still a lack of an effective theoretical calculation method for horizontal waterproof curtain reinforcement, and there is little research on the seepage laws of foundation pits under different horizontal waterproof curtain conditions. Based on Darcy's seepage theory, theoretical analysis models of deep foundation pit seepage were established considering the effect of a horizontal curtain in a highly permeable formation. Through the established models, the calculation method of the water inflow and the water pressure under the condition of a horizontal curtain was derived. Then through indoor tests, the reliability of the theoretical calculation method was verified. Furthermore, the established theoretical calculation method is used to analyze the influence of various factors on the water inflow and the water pressure, such as the ratio of hydraulic conductivity of the horizontal curtain to surrounding soil, thickness, and reinforcement position of the horizontal curtain. It is found that the hydraulic conductivity ratio has the most significant influence on the seepage characteristics of the foundation pit. Finally, the design method was applied to an example of the horizontal waterproof curtain of the foundation pit, which is located at Juyuanzhou Station in Fuzhou (China). The water inflow per unit area is $0.36 \mathrm{~m}^{3} / \mathrm{d}$ in the foundation pit, and this implies that the design method of the horizontal waterproof curtain applied for the excavation case is good and meets the requirements of design and safety.
\end{abstract}

Keywords: foundation pit; horizontal waterproof curtain; seepage characteristics; theoretical modeling; inflow prediction; highly permeable strata

\section{Introduction}

As the global urbanization process continues to expand, it has brought about problems such as shortage of urban land and traffic congestion. In order to solve these issues, the construction of urban underground space has been recognized as the most effective way. Deep excavations are an important part of underground space construction, which is usually a high-risk construction project because of great difficulty and danger during excavation. There are extremely thick Quaternary sediments with abundant groundwater resources and high water levels in the eastern coastal areas of China [1], such as Shanghai [2], Tianjin [3,4], and Fuzhou $[5,6]$. In the above environments, deep foundation excavations which lack effective groundwater control measures may result in potential geohazards and accidents such as quicksand or piping [7-9]. Thus, groundwater around a pit must be controlled by reasonable methods.

In order to address above issues, dewatering, as an auxiliary construction measure, provides dry and stable conditions for excavations, allows to increase the stability of the soil, and ensures workers' safety. There are many methods for dewatering in construction, such as sump pumping, a well point system, constructing deep wells, the educator system, waterproof curtain, etc. [10-13]. Among them, the waterproof curtain can not only be used 
as a retaining structure to ensure the stability of the foundation pit but also as a barrier to prevent groundwater seepage [14-16]. In engineering practice, the curtain and pumping wells are usually applied together to achieve a good dewatering effect in order to adapt to the increasing deep foundation pit construction [17-19].

At present, there are three main types of waterproof curtains: the full penetrating curtain [20], the partial penetrating curtain [21] and the horizontal waterproof curtain. Generally, the full penetrating curtain has the best dewatering effect as it cuts off the water inside and outside the pit. However, when encountering thick aquifers, this method requires the construction of a long curtain, which means that the construction quality will be difficult to meet the requirements and it will cost a lot [22]. However, the partial penetrating curtains have the advantages of low cost and convenient construction, thence it is used widely $[23,24]$. At the same time, the partial penetrating curtain was widely investigated by many scholars. For example, Wang proposed an optimized depth of the partial penetrating curtain, and achieved good results [25]. However, using the partial penetrating curtains alone in high-permeability soils is far from reaching the dewatering requirements. Therefore, the horizontal waterproof curtain was added to cut off the groundwater together [26], and this is a good treatment method in deep and strong permeable strata. Based on this situation, considering the "instability failure" and the "seepage failure", a simplified approach to design the waterproof bottom curtain was proposed and applied to the actual project [27]. Moreover, the cost-effective design of jet grouted water-sealing bottom curtains was presented [28]. However, none of the above studies has carried out a detailed study on the seepage characteristics of groundwater with the horizontal curtain.

Throughout the above research results, at present, the horizontal waterproof curtain reinforcement technology used for the pit bottom with high permeability is considered relatively mature. However, there is still a lack of an effective theoretical calculation method for the design of the horizontal water-sealing curtains, and there are few relevant studies on the seepage laws of the foundation pit under different horizontal sealing curtain reinforcement conditions. This research aims to analyze the seepage characters in a foundation pit by considering the horizontal waterproof curtain. Firstly, the seepage models of horizontal curtain foundation pit under different conditions is established through theoretical methods. Then, a series of indoor tests were adopted, whereby during the tests, different ratios of hydraulic conductivities of horizontal curtain to soils, thickness and positions of the horizontal waterproof curtain were employed. The various parameters of the horizontal curtain were then discussed based on the theoretical methods. Finally, an engineering example was used to illustrate the practicality of the calculation method.

\section{Phreatic Water Conditions}

\subsection{Uniform Soils}

\subsubsection{Model}

As shown in Figure 1, a mechanical analysis model of the horizontal waterproof curtain used for a deep excavation is established. The width of the foundation pit is $w$, the thickness of the curtain is $l_{2}$, the distance from the top of the horizontal curtain to the bottom of the foundation pit is $l_{3}$, and the distance from the bottom of the horizontal curtain to the bottom of the diaphragm wall is $l_{1}$. The hydraulic conductivity of the horizontal curtain is $k_{2}$, and that of soil layer is $k_{1}$. The initial head height outside the diaphragm wall is $h_{0}$, and the seepage path from the bottom of the diaphragm wall to the initial water level is $L$. The water head height at the bottom of the curtain is $h_{1}$, and that at the top is $h_{2}$. Assuming that the water level in the foundation pit drops to the bottom of the foundation pit and the head is 0 , the head height $h_{3}$ at the bottom of the foundation pit is 0 . In the calculation, the size perpendicular to the picture is taken as the unit length. 


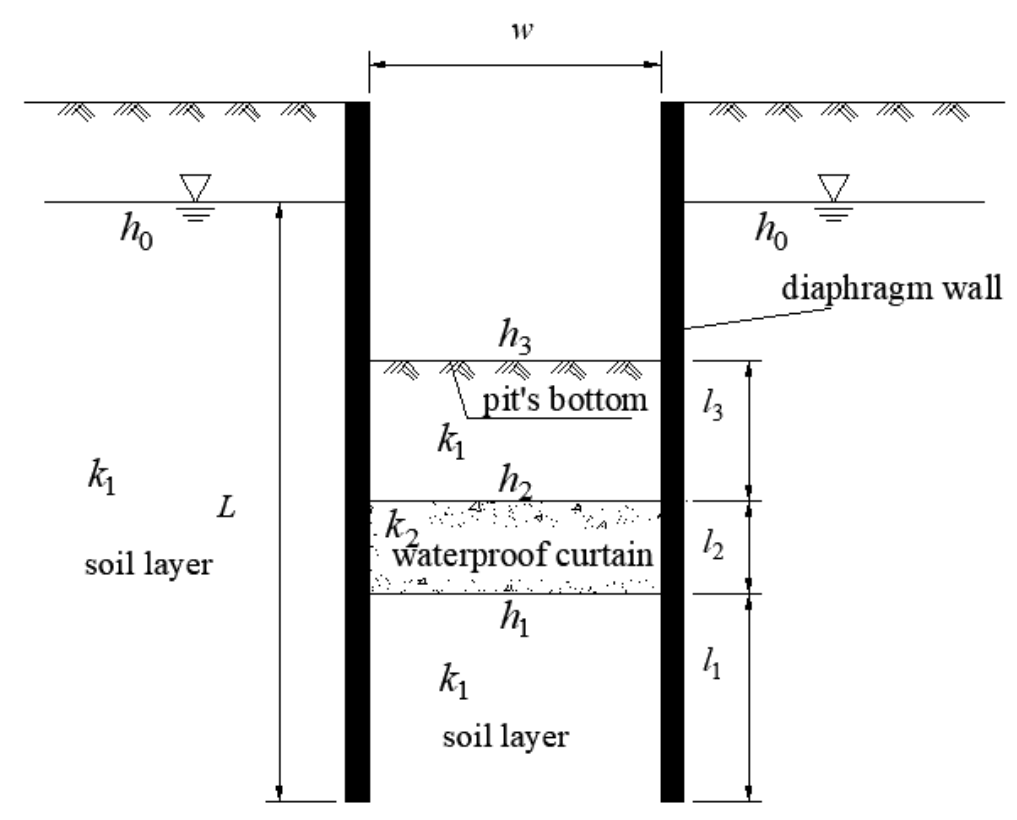

Figure 1. The schematic diagram for seepage calculation of horizontal waterproof curtain of foundation pit under the action of phreatic in homogeneous strata. ( $w$ the width of the pit; $h$ water head height; $l$ length of the seepage path; $L$ the length of the seepage path outside the pit; $k$ hydraulic conductivity).

\subsubsection{Assumption}

Cao conducted an on-site pumping test on a subway foundation pit with a horizontal curtain in Fuzhou (China) [27]. The length and width of the excavation in the reference is $200 \mathrm{~m}$ and $19.7 \mathrm{~m}$, respectively. And the thickness of the curtain is $5 \mathrm{~m}$. Other details of the parameters can be obtained from the abovementioned reference. The results showed that the water level inside the pit dropped by about $8 \mathrm{~m}$, while the water level outside the pit did not change more than $0.2 \mathrm{~m}$. Based on this, it is assumed that the groundwater located outside the pit is level and stable during the pumping process.

Generally, water inflow in the pit is huge when dewatering without the horizontal waterproof curtain in highly permeable strata. However, the field test in Fuzhou showed that after setting the horizontal curtain, the water inflow of the foundation pit was significantly reduced, and the water seepage per unit area was only $0.15 \mathrm{~m}^{3} / \mathrm{d}$. The above example proved that the seepage flow in the foundation pit with horizontal curtains is steady, and the turbulence could be ignored. Therefore, it is assumed that the water flow in the water layer obeys Darcy's Law.

A large number of scholars treat the underground diaphragm wall as an impermeable layer when doing theoretical analysis and numerical calculations [29-31]. Therefore, it is assumed that the underground diaphragm wall is impermeable.

\subsubsection{The Derivation Process}

Take a section of foundation pit with unit length for analysis. According to the principle of flow balance, the flow of each section is equal which means that the flow of the groundwater passing through the top, middle and bottom of the horizontal curtain is $Q$.

Darcy's Law is the fundamental relationship between seepage head loss $(J)$ and flow rate $(Q)$, which can be expressed as follows:

$$
Q=k A J
$$

where $Q$ is the seepage flow, $k$ is the hydraulic conductivity, $A$ is the area of the overcurrent section, and $J$ is the hydraulic gradient. 
The hydraulic gradient $J$ in Equation (1) can be expressed as follows:

$$
J=-\frac{d h}{d l}
$$

where $d h$ is the head loss of the fluid flowing through $d l$ distance.

In addition, a section with unit length is taken for analysis. Thus the $A$ in Equation (1) can be expressed as follows:

$$
A=w \times 1=w
$$

Substituting Equations (2) and (3) into Equation (1), the flow rate of an overcurrent section can be obtained as follows:

$$
Q=-k w \frac{d h}{d l}
$$

The seepage path is divided into three parts, namely, the initial water level outside the foundation pit to the horizontal curtain's bottom, the curtain's bottom to the curtain's top, and the curtain's top to the bottom of the foundation pit. The boundary parameters of the three seepage paths are shown in Table 1.

Table 1. Boundary parameters of the different seepage path.

\begin{tabular}{cccc}
\hline Boundary & First Path & Second Path & Third Path \\
\hline Initial position $(\mathrm{m})$ & 0 & $L+l_{1}$ & $L+l_{1}+l_{2}$ \\
End position $(\mathrm{m})$ & $L+l_{1}$ & $L+l_{1}+l_{2}$ & $L+l_{1}+l_{2}+l_{3}$ \\
Initial water head $(\mathrm{m})$ & $h_{0}$ & $h_{1}$ & $h_{2}$ \\
End water head $(\mathrm{m})$ & $h_{1}$ & $h_{2}$ & $h_{3}$ \\
\hline
\end{tabular}

The calculation of each seepage path is the same, and we take the first seepage path as an example for analysis: the position is 0 and water head is $h_{0}$ at the initial water level outside the foundation pit; At the bottom of the horizontal curtain, the position is $L+l_{1}$, and the end water head is $h_{1}$; The seepage coefficient is $k_{1}$. According to Equation (4), the variable separation method can be used to obtain Equation (5):

$$
Q \int_{0}^{L+l_{1}} d l=-k_{1} w \int_{h_{0}}^{h_{1}} d h
$$

Integrating Equation (5) we get Equation (6) as follows:

$$
Q=k_{1} w \frac{h_{0}-h_{1}}{L+l_{1}}
$$

Similarly, the equilibrium conditions of the second and the third paths can be obtained as follows:

$$
\begin{aligned}
& Q=k_{2} w \frac{h_{1}-h_{2}}{l_{2}} \\
& Q=k_{1} w \frac{h_{2}-h_{3}}{l_{3}}
\end{aligned}
$$

In Equations (6)-(8), $h_{3}$ is equal to 0 but there are still three unknowns, $Q, h_{1}$ and $h_{2}$. Combining Equations (6)-(8), we can find the unknowns as follows:

$$
\begin{aligned}
& h_{1}=\frac{h_{0}\left(k_{1} l_{2}+k_{2} l_{3}\right)}{k_{1} l_{2}+k_{2}\left(L+l_{1}+l_{3}\right)} \\
& h_{2}=\frac{h_{0} k_{2} l_{3}}{k_{1} l_{2}+k_{2}\left(L+l_{1}+l_{3}\right)}
\end{aligned}
$$




$$
Q=\frac{h_{0} w k_{1} k_{2}}{k_{1} l_{2}+k_{2}\left(L+l_{1}+l_{3}\right)}
$$

\subsection{Multi-Layer Soils}

\subsubsection{Model}

As shown in Figure 2, a calculation model schematic diagram is established. There are 5 soil layers outside the foundation pit, and the hydraulic conductivity and the thickness of each soil layer are different. The phreatic water level is located in the second layer, and the seepage path from the diving water level to the bottom of the pit goes through many soil layers, the distance is $l_{1}, l_{2}, l_{3}, l_{4} \ldots l_{9}$, and the hydraulic conductivity of each path is $k_{1}, k_{2}$, $k_{3}, k_{4} \ldots k_{9}$, respectively. In order to reveal the general seepage law in the multilayer soil, the following letters are used to replace specific values: the thickness of the horizontal curtain is assumed to be $l_{n-1}$; The hydraulic conductivity is $k_{n-1}$; The initial water level is set to $h_{0}$, and each seepage path at the end of $l_{n}$ is set to $h_{n}$; The water pressure at the bottom of the horizontal curtain is $h_{n-2}$, and the water pressure at the bottom of the foundation pit is $h_{n}$.

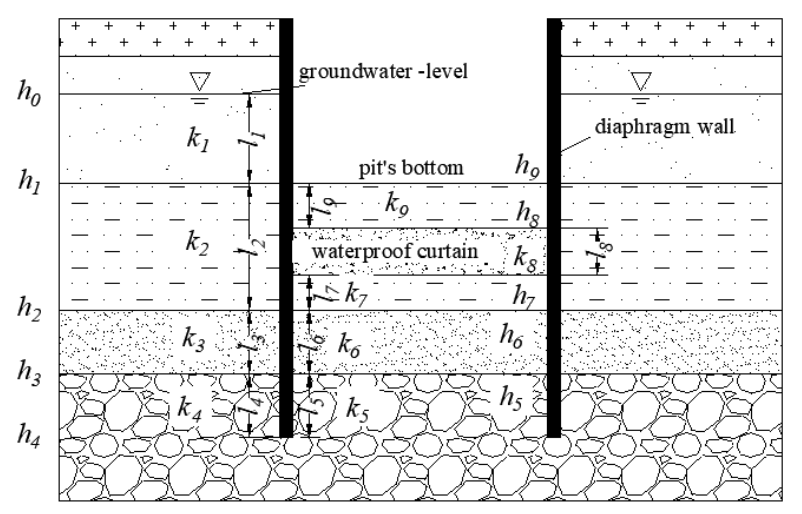

Figure 2. Schematic diagram for seepage calculation of horizontal waterproof curtain of foundation pit under the action of phreatic water in multiple strata. ( $h$ water head height; $k$ hydraulic conductivity; $l$ the length of the seepage path).

\subsubsection{The Derivation Process}

When the first seepage path is taken as an example, the boundary conditions are as follows: distance is 0 and water head is $h_{0}$ at the initial water level outside the foundation pit; At the end of the first seepage path, the distance is $l_{1}$, and water head is $h_{1}$; The hydraulic conductivity is $k_{1}$. According to Equations (4) and (5), the variable separation method is used to obtain the Equation (12):

$$
Q=\frac{k_{1} w}{l_{1}}\left(h_{0}-h_{1}\right)
$$

We set $\frac{k_{1} w}{l_{1}}$ as $a_{1}$, and transform Equation (12) to obtain Equation (13) as follows:

$$
a_{1} h_{0}-a_{1} h_{1}-Q=0
$$

Similarly, an equation similar to Equation (13) can be obtained for all other seepage paths through Equation (4). Thus, the system of Equation (14) can be obtained by combining the n-segment paths obtained:

$$
\left.\begin{array}{l}
a_{1} h_{0}-a_{1} h_{1}-Q=0 \\
a_{2} h_{1}-a_{2} h_{2}-Q=0 \\
\vdots \\
a_{n-1} h_{n-2}-a_{n-1} h_{n-1}-Q=0 \\
a_{n} h_{n-1}-a_{n} h_{n}-Q=0
\end{array}\right\}
$$


The system of Equation (14) contains $n$ equations, with a total of $n$ unknowns, $h_{1} \sim h_{n-1}$ and $Q$. Equation (14) is rewritten as the following Equation (15) for the convenience of calculation:

$$
\left[\begin{array}{cccccccc}
a_{1} & 0 & 0 & 0 & \ldots & 0 & 0 & 1 \\
a_{2} & -a_{2} & 0 & 0 & \ldots & 0 & 0 & -1 \\
0 & a_{3} & -a_{3} & 0 & \ldots & 0 & 0 & -1 \\
& & & & \ldots & & & \\
0 & \cdots & 0 & 0 & a_{n-2} & -a_{n-2} & & \\
0 & \cdots & 0 & 0 & 0 & a_{n-1} & -a_{n-1} & -1 \\
0 & \cdots & 0 & 0 & 0 & 0 & a_{n} & -1
\end{array}\right]\left[\begin{array}{c}
h_{1} \\
h_{2} \\
h_{3} \\
\vdots \\
h_{n-2} \\
h_{n-1} \\
Q
\end{array}\right]=\left[\begin{array}{c}
a_{1} h_{0} \\
0 \\
0 \\
\vdots \\
0 \\
0 \\
a_{n} h_{n}
\end{array}\right]
$$

By solving Equation (15), the water pressure and the water inflow at any soil layer in the foundation pit can be obtained.

\section{Confined Water Conditions}

\subsection{Model}

As shown in Figure 3, the mechanical model of horizontal waterproof curtain with confined water was established. The physical meaning of each parameter in Figure 3 is the same as that in Figure 1, which will not be repeated here. Unlike the phreatic model, the confined water has no free surface, but the pressure $p$ at the bottom of the diaphragm can be converted to head height $h_{0}$. The entire seepage path is from the bottom of the diaphragm wall to the bottom of the pit. Since no stagnant water is allowed in the foundation pit, the height of the water head height $\mathrm{h} 3$ at the bottom of the foundation pit is zero.

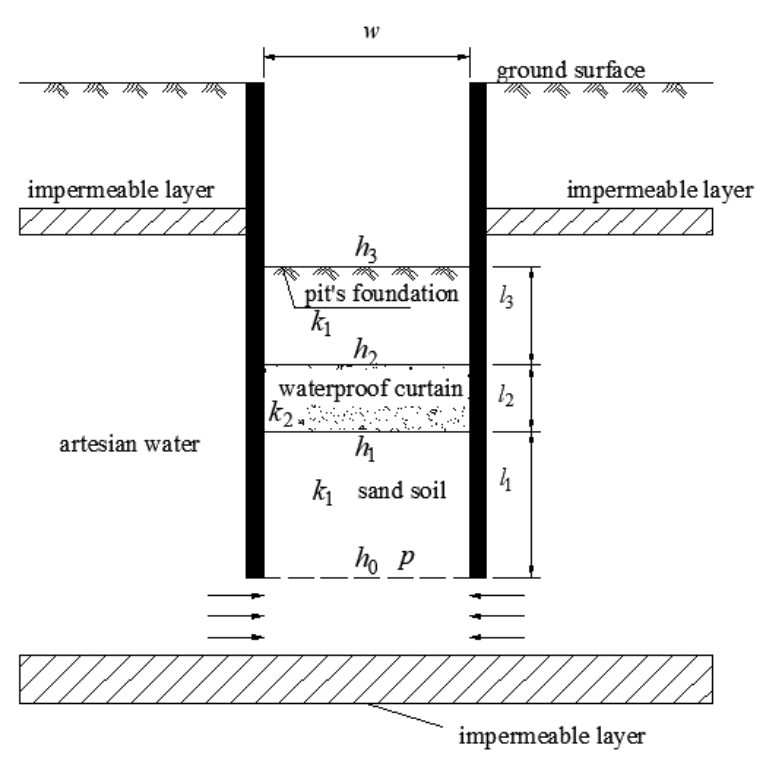

Figure 3. Schematic diagram for seepage calculation of horizontal waterproof curtain of foundation pit under the action of artesian water. ( $h$ water head height; $l$ the length of the seepage path; $k$ hydraulic conductivity; $w$ width of the pit; $p$ water pressure at the bottom of the diaphragm wall).

\subsection{The Derivation Process}

Compared with the phreatic condition, there is no seepage path from the free phreatic surface outside the foundation pit to the bottom of the diaphragm wall under the action of confined water, which indicates that there is no head loss outside the diaphragm wall in Figure 3. The calculation method for the seepage calculation of artesian water only need to 
change the first seepage path from $\left(\mathrm{L}+l_{1}\right)$ in the equations of phreatic to $l_{1}$. The calculation formulas about water pressure and water inflow at the bottom of the curtain are as follows:

$$
\begin{aligned}
& h_{1}=\frac{h_{0}\left(k_{1} l_{2}+k_{2} l_{3}\right)}{k_{1} l_{2}+k_{2}\left(l_{1}+l_{3}\right)} \\
& Q=\frac{h_{0} w k_{1} k_{2}}{k_{1} l_{2}+k_{2}\left(l_{1}+l_{3}\right)}
\end{aligned}
$$

\section{Experiments}

In order to verify the correctness of the above calculation theory, an indoor model test was designed. On the one hand, the artesian water and phreatic have the same calculation principle. On the other hand, the artesian water test device has the characteristics of simplicity, easy operation and high efficiency. Therefore, an artesian water test model was adopted.

\subsection{Experiment Design}

By referring to the paper on dewatering of foundation pit model test [32,33], the size of the model box is determined as length $\times$ width $\times$ height $=1.2 \times 0.4 \times 0.8 \mathrm{~m}^{3}$ and the test box is shown in Figure 4. The bottom of the dewatering well and the filling surface are 55 and $75 \mathrm{~cm}$, respectively. In order to study the changes of water level and water pressure in the soil, a pressure measuring hole was arranged in the inside of the model box every $10 \mathrm{~cm}$ from the bottom up along the depth direction. A total of seven pressure measuring holes with a diameter of $1.5 \mathrm{~cm}$ were arranged and connected to the pressure measuring meter. Two water supply holes were provided on both sides of the bottom of the model box.

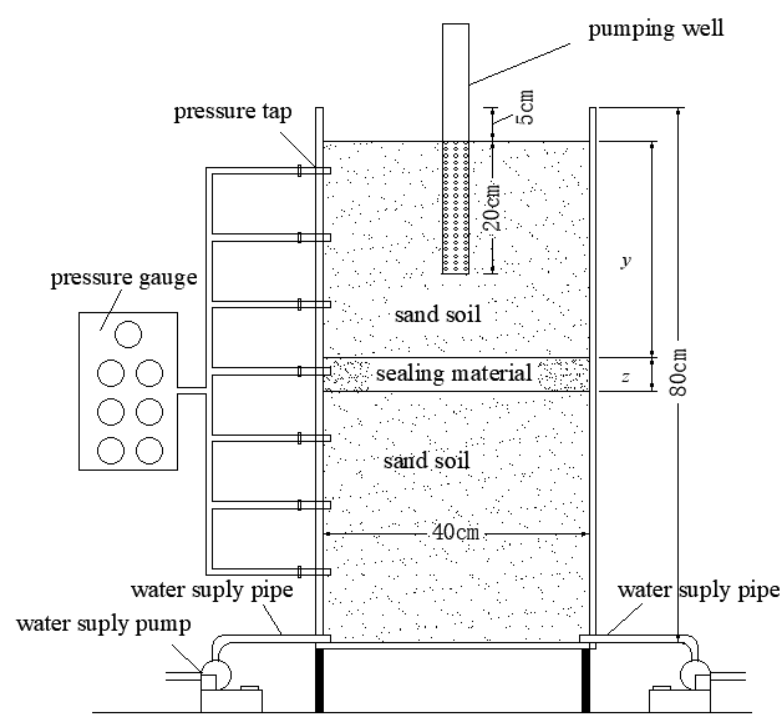

Figure 4. Schematic diagram of test model box. ( $z$ the thickness of the curtain; $y$ the distance between the curtain and the top surface of the fill).

Each water supply hole was connected to the booster pump. The initial water head $h_{0}$ in the test is set to $5 \mathrm{~cm}$ by changing the water supply pressure of the pump. In the test, the power of the pump was adjusted so that the pressure gauge reading at $70 \mathrm{~cm}$ in the model box was close to 0 , that is, the water level remained stable at $70 \mathrm{~cm}$. After the water level stabilizes, the water inflow of the foundation pit model is recorded by reading the flow rate of the pumping well.

In order to obtain the variation law of water pressure and the water inflow, three parameters were considered: the hydraulic conductivity ratio of the horizontal curtain $(\beta)$, the distance between the curtain and the bottom of foundation pit $(y)$, and the thickness of the curtain $(z)$. Thus seven working conditions are set up, and the parameters of each working condition are shown in Table 2 . The medium-coarse sand with a hydraulic 
conductivity of $8.13 \mathrm{~m} / \mathrm{d}$ was selected as the test soil. In addition, clay and sand are mixed in different proportions to simulate horizontal waterproof curtains with different moisture contents. The hydraulic conductivity ratio $(\beta)$ is equal to the hydraulic conductivity of the water curtain divided by the hydraulic conductivity of the surrounding soil. When the hydraulic conductivity ratio is 1 , it is equivalent to pumping water directly from the drainage well without setting a horizontal curtain.

Table 2. Parameters of each working condition.

\begin{tabular}{cccc}
\hline Test Conditions & $\boldsymbol{y} \mathbf{( \mathbf { c m } )}$ & $\boldsymbol{z} \mathbf{( \mathbf { c m } )}$ & $\boldsymbol{\beta}$ \\
\hline 1 & 20 & 5 & 0.223 \\
2 & 20 & 5 & 0.057 \\
3 & 20 & 8 & 0.057 \\
4 & 30 & 5 & 0.057 \\
5 & 40 & 5 & 0.057 \\
6 & - & - & 1 \\
7 & 20 & 5 & 0
\end{tabular}

$y$ the distance between the curtain and the bottom of foundation pit; $z$ the thickness of the curtain; $\beta$ the hydraulic conductivity of the horizontal curtain to undisturbed soil.

\subsection{Comparison of Test and Calculation Results}

\subsubsection{Verification of Water Inflow}

Through the model tests, the measured water inflow of the foundation pit with seven working conditions can be obtained. Then, Equation (17) is used to calculate the theoretical value of pit water inflow in each working condition, and the calculated results are compared with the experimental results. The comparison data results are shown in Table 3, and the comparison curves are shown in Figure 5.

Table 3. The comparison of water inflow test and calculation results of foundation pit under different conditions.

\begin{tabular}{|c|c|c|c|c|c|c|}
\hline $\begin{array}{c}\text { Test } \\
\text { Conditions }\end{array}$ & $y(\mathrm{~cm})$ & $z(\mathrm{~cm})$ & $\beta$ & $\begin{array}{l}\text { Experimental } \\
\text { Results (L/h) }\end{array}$ & $\begin{array}{c}\text { Calculated } \\
\text { Results (L/h) }\end{array}$ & Relative Error \\
\hline 1 & 20 & 5 & 0.223 & 11.32 & 9.30 & $17.85 \%$ \\
\hline 2 & 20 & 5 & 0.057 & 6.85 & 5.32 & $22.28 \%$ \\
\hline 3 & 20 & 8 & 0.057 & 5.13 & 4.02 & $21.68 \%$ \\
\hline 4 & 30 & 5 & 0.057 & 6.27 & 5.32 & $15.10 \%$ \\
\hline 5 & 40 & 5 & 0.057 & 6.41 & 5.32 & $16.95 \%$ \\
\hline 6 & - & - & 1 & 15.32 & 11.61 & $24.19 \%$ \\
\hline 7 & 20 & 5 & 0.0001 & 0 & 0 & $0 \%$ \\
\hline
\end{tabular}

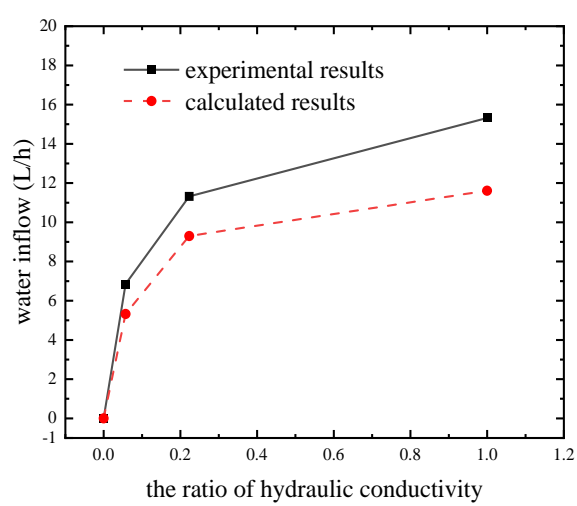

(a) hydraulic conductivity

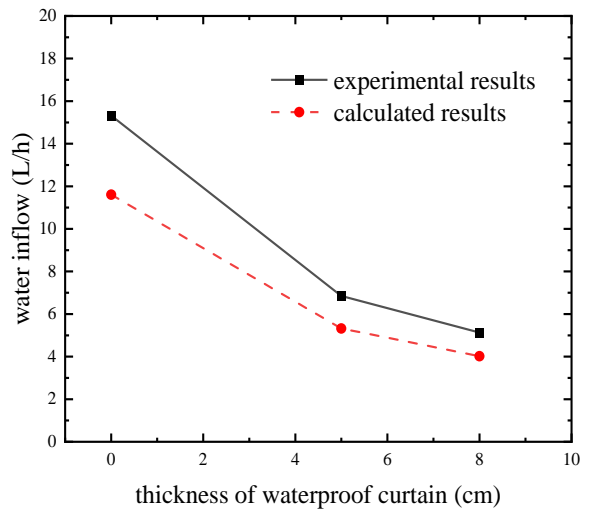

(b) thickness

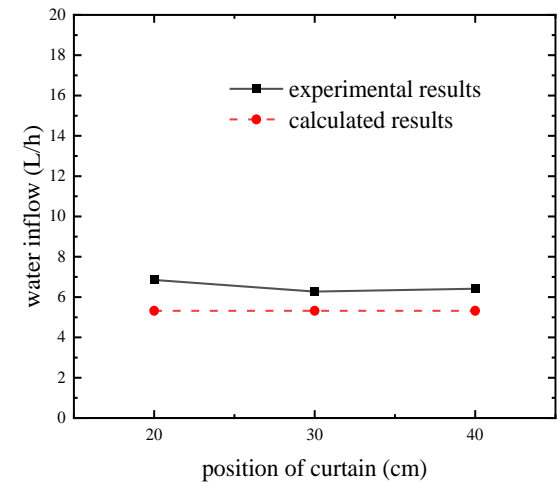

(c) position

Figure 5. Comparison curves of pit water inflow with different parameters. (a) influence of hydraulic conductivity ratio on water inflow; (b) influence of curtain's thickness on water inflow; (c) influence of curtain's position on water inflow. 
(1) Water inflow comparison with different hydraulic conductivity ratios

In the condition that $z$ is $5 \mathrm{~cm}$ and $y$ is $20 \mathrm{~cm}$, by changing $\beta$ and combining working conditions 7, 2, 1 and 6, the comparison curves of experimental data and theoretical calculation results are shown in Figure 5a. It can be seen from the Table 3 that the calculated results for the water inflow of the foundation pit with different hydraulic conductivity ratios are similar to the test results, and the theoretical values are slightly smaller than the test values. The relative error of the two methods is controlled at about $20 \%$, and the curve change trend of the two methods is consistent.

(2) Water inflow comparison with different thickness of the curtain

In the condition that $\beta$ is 0.057 and $y$ is $20 \mathrm{~cm}$, by changing $z$ and combining working conditions 6, 2 and 3, the comparison curves of the experimental data and theoretical calculation results are shown in Figure $5 \mathrm{~b}$. As can be seen from the data comparison in the Table 3, the calculated results for water inflow under the different thickness of horizontal curtain are similar to the experimental results, and the theoretical values are slightly smaller than the observed values. The relative error of the two methods is controlled at about $20 \%$, and the curve change trend of the two ways is consistent.

(3) Water inflow comparison with different curtain positions

In the condition of keeping $\beta$ at 0.057 and $z$ at $5 \mathrm{~cm}$, by changing $y$ and combining working conditions 2, 4 and 5, the comparison curves of experimental data and theoretical calculation results are shown in Figure 5c. From the data comparison in the Table 3, it can be seen that the water inflow of foundation pit with changing curtain depth remains unchanged when thickness and hydraulic conductivity are constant. There is little difference between the theoretical formula calculation result and the test result, and the model test result is also close to the horizontal line. The theoretical calculation result is consistent with the law reflected by the test result.

\subsubsection{Verification of Water Pressure}

The results of the head pressure tests at the bottom of the horizontal curtain and the calculation results obtained by Equation (16) are compared with different parameters, as shown in Table 4 and Figure 6.

Table 4. Comparison of experimental results and calculated results of water pressure under different working conditions.

\begin{tabular}{|c|c|c|c|c|c|c|}
\hline $\begin{array}{c}\text { Test } \\
\text { Conditions }\end{array}$ & $Y(\mathrm{~cm})$ & $z(\mathrm{~cm})$ & $\beta$ & $\begin{array}{c}\text { Experimental } \\
\text { Results (cm) }\end{array}$ & $\begin{array}{l}\text { Calculated } \\
\text { Results (cm) }\end{array}$ & Relative Error \\
\hline 1 & 20 & 5 & 0.223 & 2.830 & 2.140 & $24.37 \%$ \\
\hline 2 & 20 & 5 & 0.057 & 3.812 & 3.363 & $11.78 \%$ \\
\hline 3 & 20 & 8 & 0.057 & 4.212 & 3.839 & $8.86 \%$ \\
\hline 4 & 30 & 5 & 0.057 & 4.000 & 3.690 & $7.74 \%$ \\
\hline 5 & 40 & 5 & 0.057 & 4.521 & 4.018 & $11.13 \%$ \\
\hline 6 & - & - & 1 & 2.134 & 1.429 & $33.06 \%$ \\
\hline 7 & 20 & 5 & 0.0001 & 5.000 & 4.995 & $0.100 \%$ \\
\hline
\end{tabular}




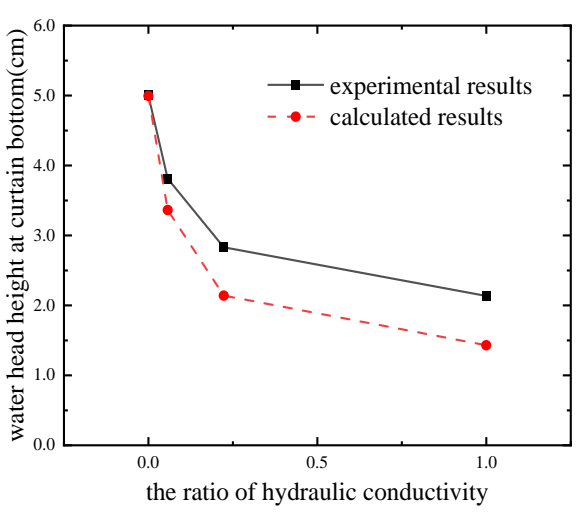

(a) hydraulic conductivity

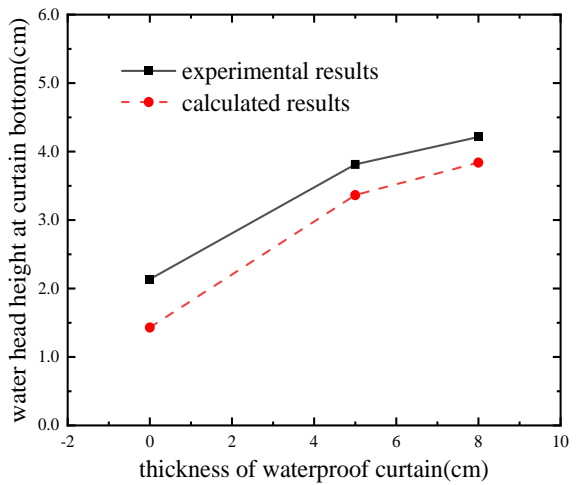

(b) thickness

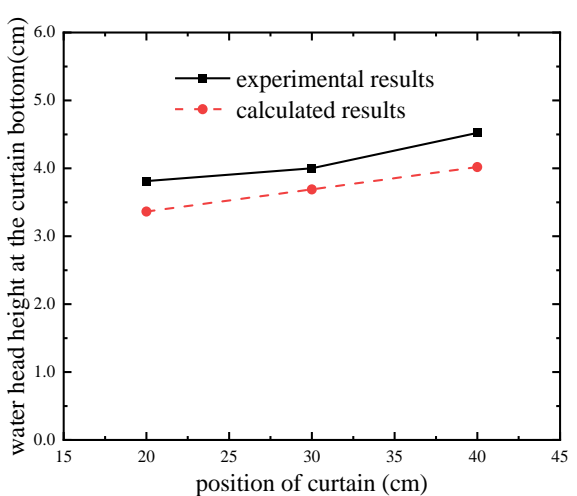

(c) position

Figure 6. Comparison curves of water head height with different parameters. (a) influence of hydraulic conductivity ratio on water pressure; (b) influence of curtain's thickness on water pressure; (c) influence of curtain's position on water pressure.

(1) Water pressure comparison with different hydraulic conductivity ratios

In the condition that $z$ is $5 \mathrm{~cm}$ and $y$ is $20 \mathrm{~cm}$, by changing $\beta$ and combining working conditions 7, 2, 1 and 6, the experimental data and theoretical calculation results of water pressure in the bottom of the curtain are compared. It can be seen from the data in the Table 3 and the comparison Figure 6 a that the calculated results of water head with different hydraulic conductivity ratios are similar to the test results (except for condition 6 which will discuss in Section 4.3. Error Analysis), and the two curves have the same change trend. Therefore, the theoretical calculation method is reliable.

\section{(2) Water pressure comparison with different thickness}

In the condition that $\beta$ is maintained at 0.057 and the $y$ is $20 \mathrm{~cm}$, by changing $z$ and combining working conditions 6, 2 and 3, the comparison curves of the experimental data and theoretical results are compared. It can be seen from the Table 3 and the Figure $6 \mathrm{~b}$ that the calculation results with different thickness are similar to the test results (except for working condition 6 which will discuss in Section 4.3. Error Analysis). The relative error is controlled at about $10 \%$, and the curve change trend is consistent, which reflects the same Law. Therefore, the theoretical method is reliable.

(3) Water pressure comparison with different curtain positions

In the condition of keeping $\beta$ is 0.057 and $z$ is $5 \mathrm{~cm}$, by changing $y$ and combining working conditions 2,4 and 5 , the comparison curve of the experimental data and theoretical calculation results are compared. It can be seen from Table 3 and Figure $6 \mathrm{c}$ that the calculation results are similar to the test results. The relative error of the two methods is about $10 \%$, and the curve change trend of the two ways is consistent. Therefore, the theoretical way is reliable.

\subsection{Error Analysis}

When deriving the theoretical formula, we assumed that the water level is horizontal during the pumping process. However, due to the limited number of pumping wells, the validity of this theoretical hypothesis cannot be guaranteed during the test. In the actual test, the bottom water level of the foundation pit will appear the water cone of depression [34], as shown in Figure 7. Therefore, the measured water inflow in the experiment will be greater than the theoretical calculation result. For the same reason, the actual zero momentum head will be lower than the calculation assumption, resulting in the measured pressure at the bottom of the curtain higher than the theoretical value. Especially for working condition 6 without the curtain, the phenomenon of the water cone of depression is more obvious. Therefore, the calculated and measured results are more different than other operating conditions. 


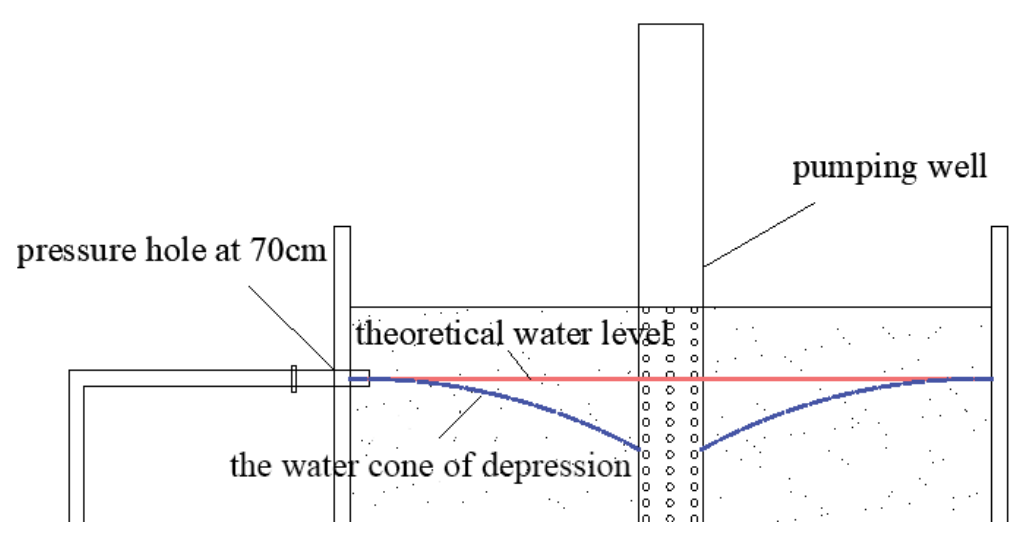

Figure 7. Diagram of water line.

The calculation model assumes that the water inflow is consistent along the direction of length, which is reasonable for the subway foundation pit with a large ratio of length to width. The aspect ratio of the model box is too small ( $1.2 \mathrm{~m}$ long and $0.4 \mathrm{~m}$ wide), which leads to discrepancies between the test and the hypothesis, resulting in a certain error in the theoretical calculation. In addition, considering that the actual water level along the length direction is also lower than the calculated water level, the measured water inflow and head height will be larger than the calculated results.

The above error analysis is only for the deviation produced by the test box. In the actual construction, the calculation error will be reduced for the reason that the foundation pit is set with a horizontal curtain and the ratio of length to width are relatively large. Therefore, the theoretical analysis and calculation method proposed in this paper is feasible.

\section{Result and Discussion}

\subsection{Curtain in Single Layer Soil Condition}

The simplified model of the foundation pit is shown in Figure 8. The width of the foundation pit is $20.0 \mathrm{~m}$, the burial depth of diaphragm wall is $35.0 \mathrm{~m}$, the bottom of the foundation pit is $10.0 \mathrm{~m}$ from the ground, and the underground diving level is $H \mathrm{~m}$ higher than the bottom of the foundation pit. The thickness of the horizontal curtain is $z \mathrm{~m}$, the top of the curtain is $l_{1} \mathrm{~m}$ from the bottom of the foundation pit, and the bottom of the curtain is $l_{2} \mathrm{~m}$ from the bottom of the diaphragm wall. And the seepage path from the bottom of the diaphragm wall to the initial water level is $L$. The entire foundation pit is located in a homogeneous stratum, with the stratum hydraulic conductivity $k_{1}$ and the horizontal curtain hydraulic conductivity is $k_{2}$ so the ratio $(\beta)$ of the hydraulic conductivity is $k_{2} / k_{1}$.

The theoretical method is used to calculate the water inflow in the foundation pit and the head height at the bottom of the curtain with different parameters $\left(\beta, z\right.$ and $\left.l_{1}\right)$, and the change law of the two is analyzed. The parameters of the foundation pit were put into Equations (9) and (11). The formula for calculating the head height $\left(h_{2}\right)$ at the bottom of the waterproof curtain and the water flow per unit length $(Q)$ of the foundation pit could be simplified as follows:

$$
\begin{gathered}
h_{2}=\frac{H}{1+\frac{\left(l_{2}+L\right) \beta}{z+l_{1} \beta}} \\
Q=\frac{H w \beta}{\left(l_{2}+L+l_{1}\right) \beta+z} k_{1}
\end{gathered}
$$




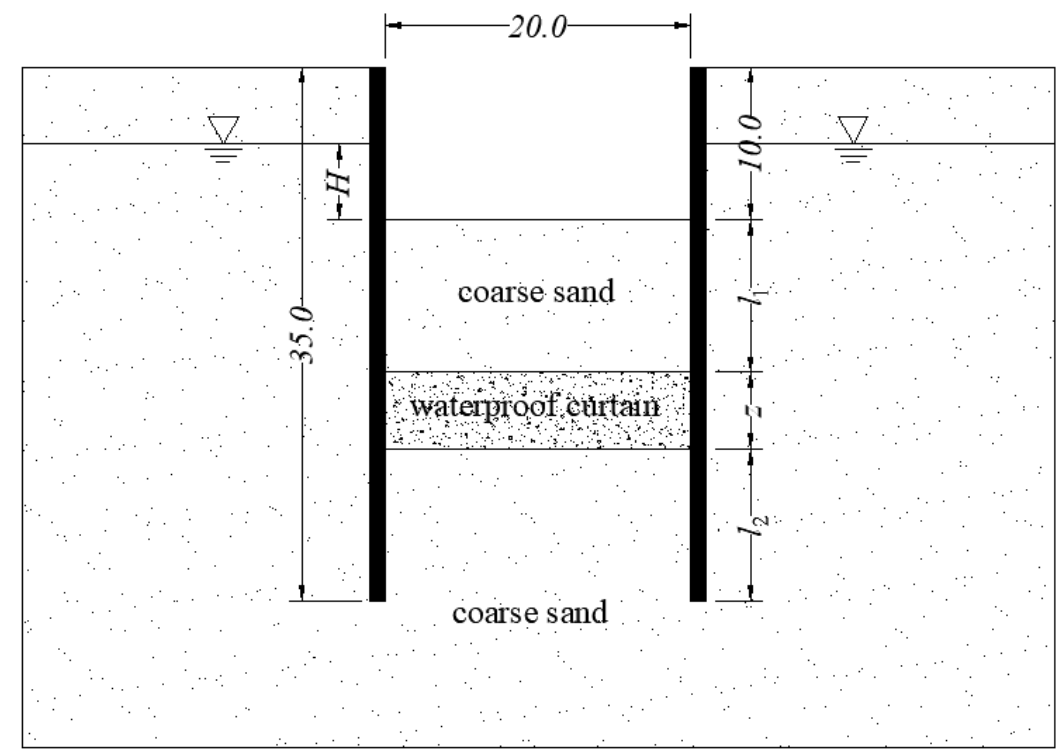

Figure 8. Simplified model diagram of a foundation pit. ( $H$ the height difference between the water level outside the pit and the bottom of the pit; $l$ the length of the seepage path; $z$ the thickness of the curtain).

\subsubsection{The Ratio of Hydraulic Conductivity}

As can be seen from Equation (18), when $\beta$ tends to 0 , the denominator tends to 0 , thus the head height $h_{2}$ tends to H. It can be seen from Equation (19) that the $\beta$, as a factor of molecules, is crucial to the control of seepage flow. By controlling $l_{1}, \mathrm{z}$ to be $10 \mathrm{~m}, 5 \mathrm{~m}$ and changing the $\beta$, different depth of water level and other parameters are substituted into Equations (18) and (19). The water inflow and the water pressure at the bottom of the curtain were obtained, as shown in Figures 9 and 10, respectively.

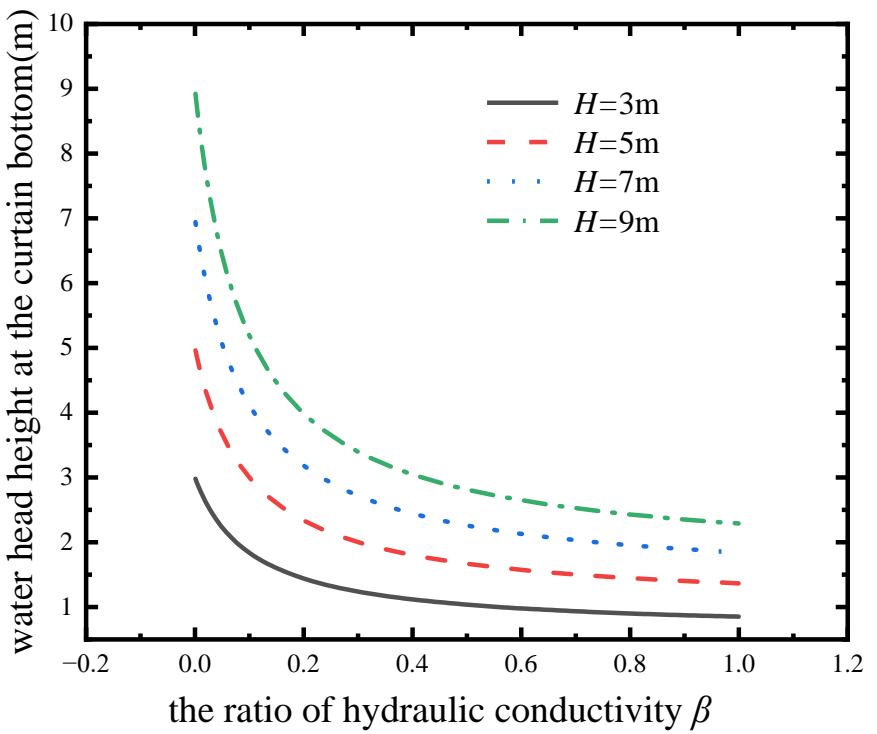

Figure 9. Variation of water head under different hydraulic conductivity ratios.

It can be seen from Figures 9 and 10 that at different water level heights when the $\beta$ increases, the $h_{2}$ drops rapidly and the water inflow per unit length rises sharply. When the hydraulic conductivity ratio is 0.01 , the head height is $3-4$ times that of no curtain, but the water inflow is only $10 \%$ of that without the curtain. When the hydraulic conductivity ratio was 0.001 , the water inflow was only $1.8 \%$ of that without the curtain. The above results indicate that the parameter $\beta$ has a significant influence on the seepage characteristics, so 
the horizontal curtain has an excellent waterproof performance in actual project as it can reduce the ratio of the hydraulic conductivity significantly.

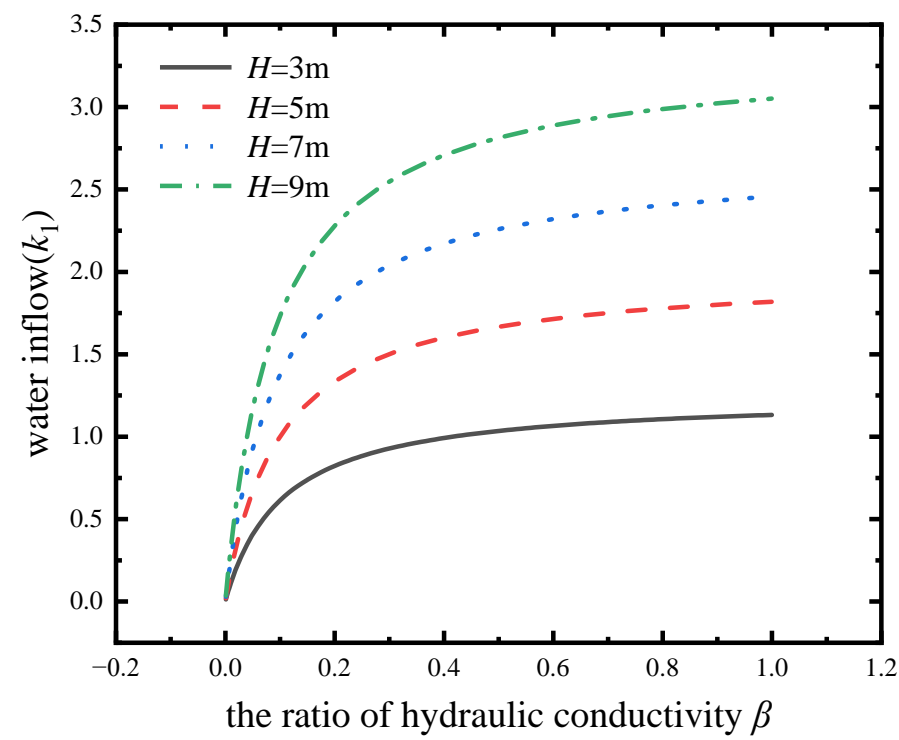

Figure 10. Variation of water inflow with different hydraulic conductivity ratios.

\subsubsection{The Thickness of Waterproof Curtain}

It can be seen from Equation (18) that the denominator will decrease as $\mathrm{z}$ increases so that the height of the water head at the bottom of the curtain increases. It can be seen from Equation (19) that the value of $z$ exists in the denominator as an addend. When $\beta$ is a constant value, the denominator increases as $z$ increases so that $Q$ will decrease. And when $\beta$ is very small, the denominator tends to 0 , and the $z$ value mainly controls the size of the denominator, so that the change of the $z$ value has a significant influence on the water inflow. By controlling $H$ to $5 \mathrm{~m}$ and $l_{1}$ to $10 \mathrm{~m}$, changing the size of $z$, and substituting different hydraulic conductivity ratios and various parameters into Equations (18) and (19), the changes in water pressure at the bottom of the curtain under different thickness $z$ are shown in Figure 11. As shown, the change curve of water inflow per unit length of the foundation pit is shown in Figure 12.

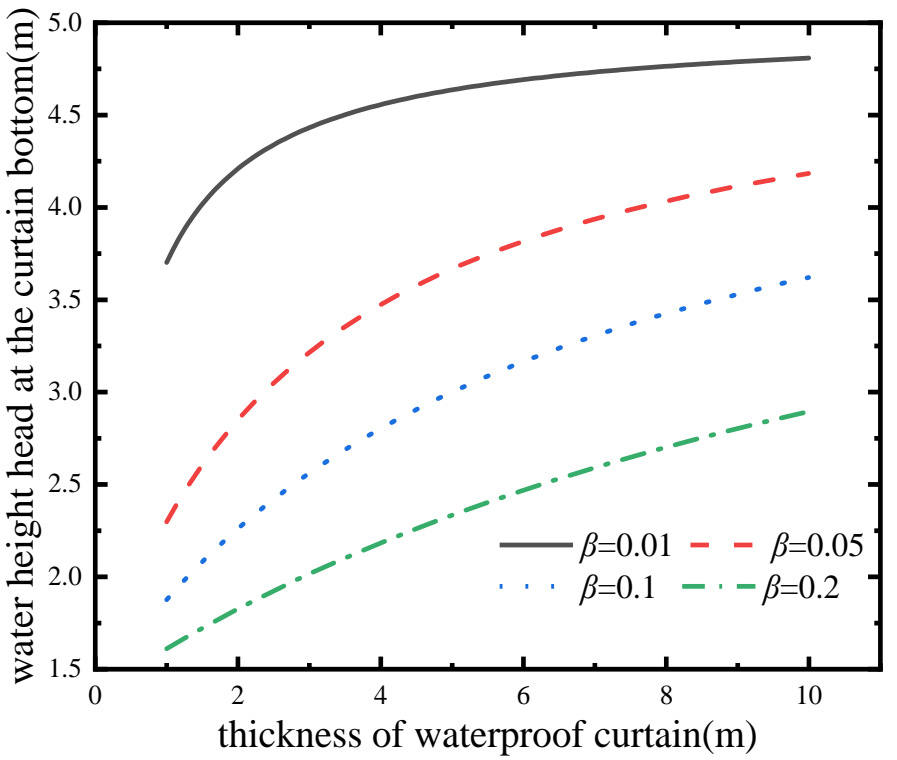

Figure 11. Variation of bottom water head with different thickness. 


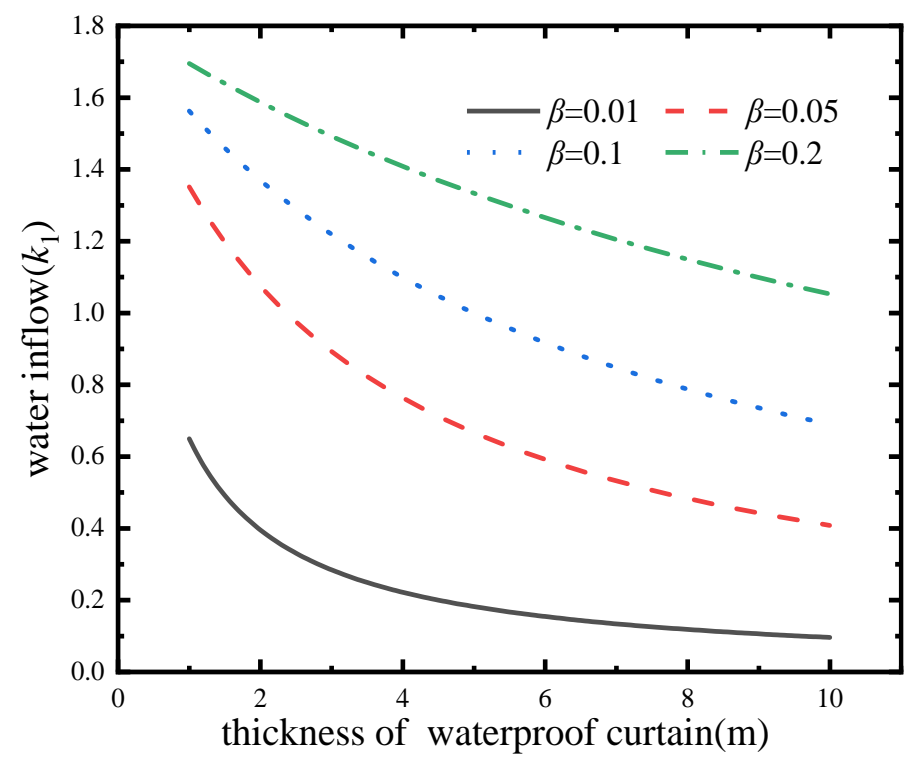

Figure 12. Variation of water inflow with different thickness.

It can be seen from Figures 11 and 12 that the water pressure increases, the water inflow decreases, and the curve change speed becomes slower and slower when thickness of the curtain increases. This shows that after the thickness of the curtain is increased to a certain range, the water blocking effect of increasing the thickness is no longer obvious. On the contrary, increasing the thickness at this time will increase the engineering cost, resulting in a decrease in cost performance. It can also be seen that the smaller the hydraulic conductivity, the more obvious performance for stopping the water, which once again shows that the hydraulic conductivity is very important. Comparing the results with Figures 9 and 10, it can be seen that the thickness of the horizontal curtain is not as important as the ratio of the hydraulic conductivity.

\subsubsection{Curtain Position}

It can be seen from Equation (18) that the change of the position $l_{1}$ of the horizontal curtain affects the value in the denominator. The position related $l_{1}$ and $L+l_{2}$ are all calculated after being multiplied by $\beta$. Therefore, when $\beta$ is very small, the head height does not change. It can be seen from Equation (19) that the change of $l_{1}$ and $l_{2}$ will not affect the sum of the two, so under the same hydraulic conductivity ratio, $Q$ does not change with the shift of $l_{1}$. By controlling $H, z$ to $5 \mathrm{~m}$ and the hydraulic conductivity ratio to 0.01 , the position of the horizontal curtain is changed to $l_{1}$, and different hydraulic conductivity ratios and various parameters are substituted into Equations (18) and (19). The changes of water head and water inflow with different curtain positions are shown in Figures 13 and 14 respectively.

It can be seen from Figure 13 that the change of the curtain position has little effect on the water head height. And as the hydraulic conductivity decreases, the change becomes less obvious. Figure 14 reflects that the water inflow does not change with the thickness of the curtain. In summary, the effect of the curtain position on the seepage characteristics is extremely weak. 


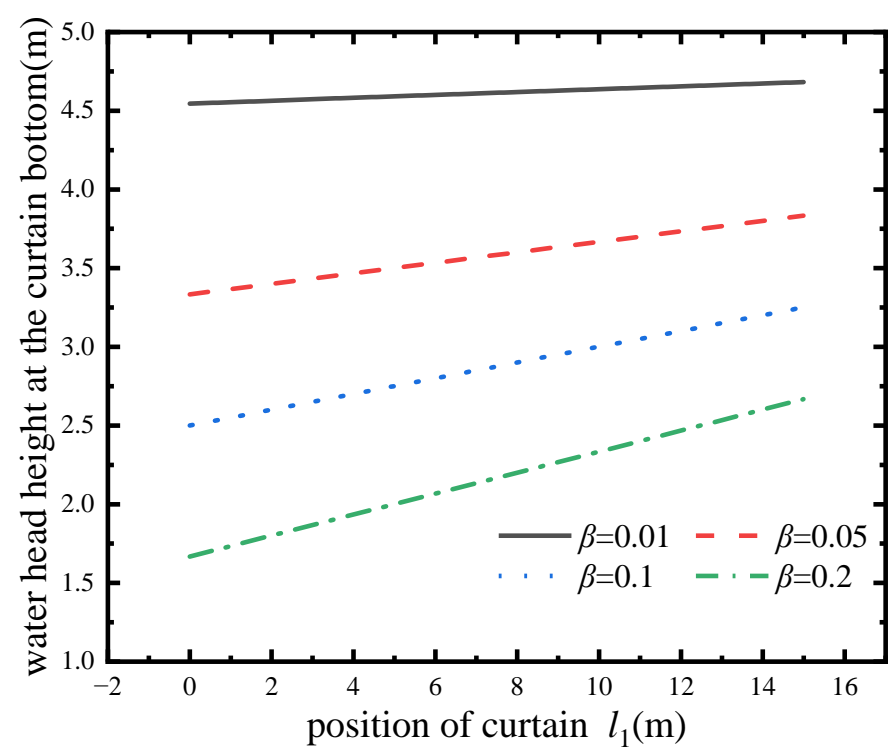

Figure 13. Variation of the water pressure with different positions.

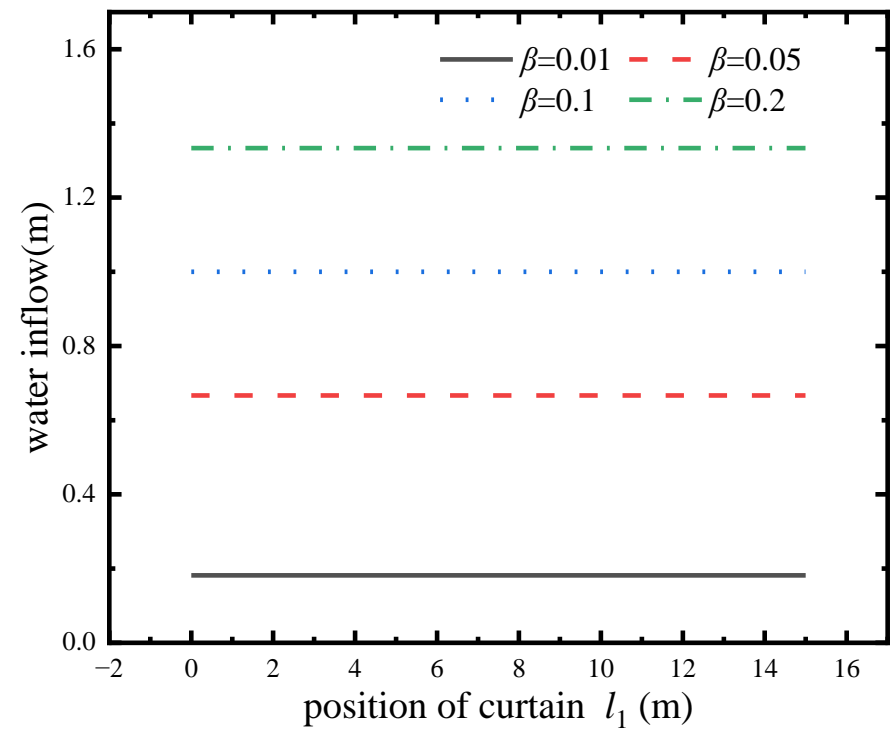

Figure 14. Variation of water inflow with different positions.

\subsection{Curtain in Multiple Layers Soil Condition}

Taking the calculation model Figure 15 as an example, the stratum around the foundation pit is dominated by coarse sand with good water permeability, and in the middle is a sandy loam soil layer with weak water permeability. The depth of the foundation pit is $10.0 \mathrm{~m}$, the depth of the diaphragm wall is $35.0 \mathrm{~m}$, and the top of the sandy loam soil layer is $25.0 \mathrm{~m}$ from the ground surface with a thickness of $5 \mathrm{~m}$. The bottom of the horizontal waterproof curtain is $y \mathrm{~m}$ from the bottom of the ground connecting wall, and the thickness is $z \mathrm{~m}$. The hydraulic conductivity of the coarse sand layer was taken as $30 \mathrm{~m} / \mathrm{d}$, and that of the sandy loam soil layer was $0.05 \mathrm{~m} / \mathrm{d}$. 


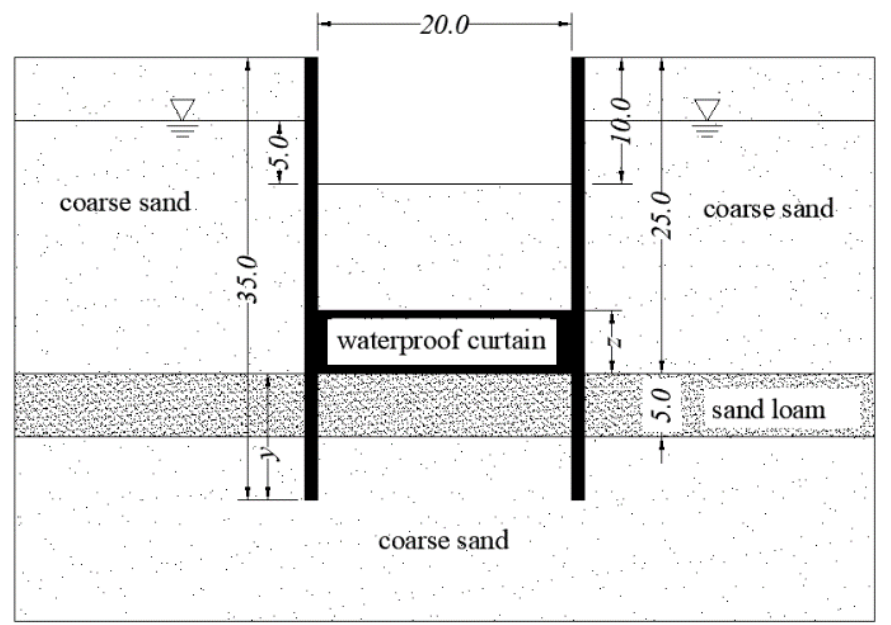

Figure 15. Multi-aquifer calculation model diagram. ( $z$ the thickness of the curtain; $y$ the distance between the curtain's bottom and the diaphragm wall's bottom).

\subsubsection{The Ratio of Hydraulic Conductivity}

By controlling the position $y$ to be $10 \mathrm{~m}$ and the thickness $z$ to be $5 \mathrm{~m}$, the hydraulic conductivity ratio of the horizontal curtain was changed, and the geological and curtain parameters of the foundation pit were put into Equation (15). The changes of water inflow and water pressure with different coefficient ratios are shown in Figure 16a,b respectively. It can be seen from Figure 16 that both the water inflow and the water pressure change nonlinearly with $\beta$, and the degree of change is getting slower and slower. Therefore, the permeability coefficient ratio has a significant effect on the seepage flow.

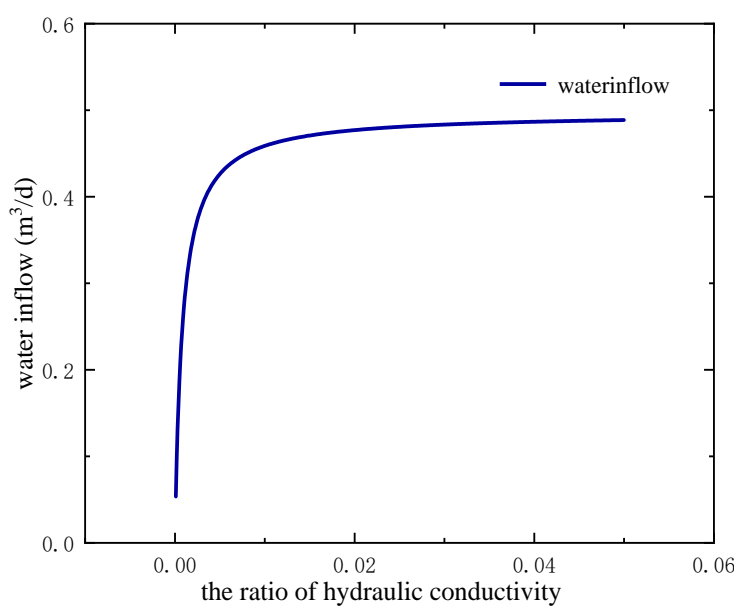

(a) influence of hydraulic conductivity ratio on water inflow

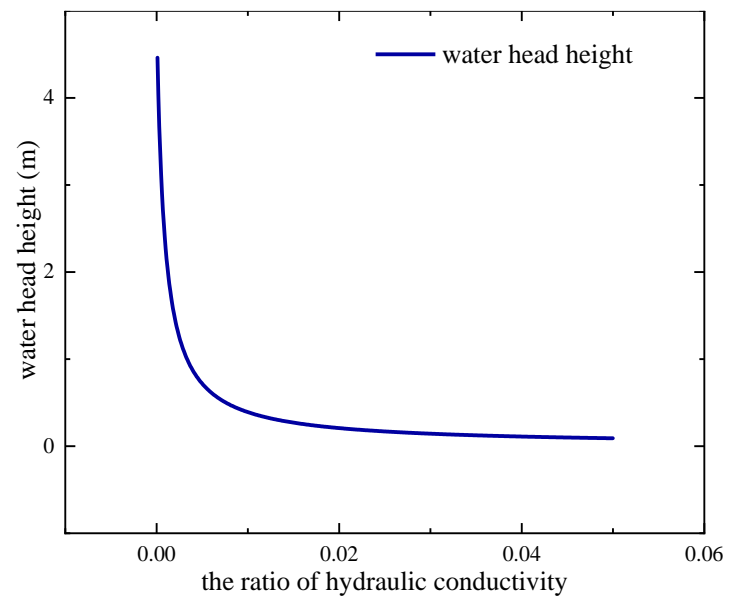

(b) influence of hydraulic conductivity ratio on water pressure

Figure 16. Effect of hydraulic conductivity ratio on result.

\subsubsection{The Thickness of Waterproof Curtain}

By controlling the position $y$ to be $10 \mathrm{~m}$, and the hydraulic conductivity of the horizontal curtain to be $6.9 \times 10^{-3} \mathrm{~m}^{3} / \mathrm{d}$, by changing the thickness $z$, the geological parameters of the subway foundation pit and the curtain are put into Equation (15). The changes of water inflow and water pressure with different thickness are shown in Figure 17a,b respectively. It can be seen from Figure 17 that both the water inflow and the water pressure change nonlinearly with $z$, and the degree of change is getting slower and slower. Therefore, the thickness of the curtain has an effect on the water intake and water pressure. It can be 
conducted that the thickness of the curtain has an obvious effect on the water inflow and the pressure.

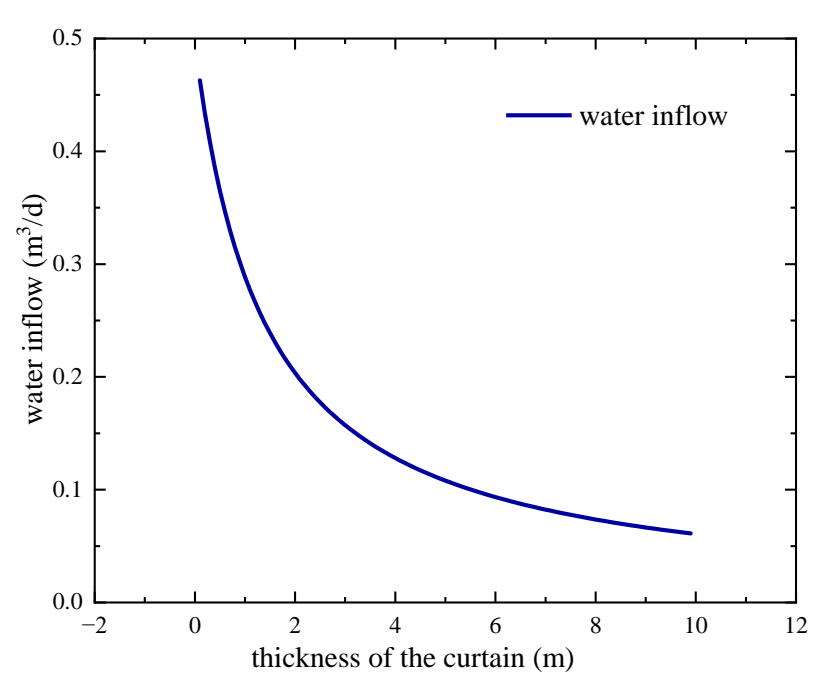

(a) influence of curtain's thickness on water inflow

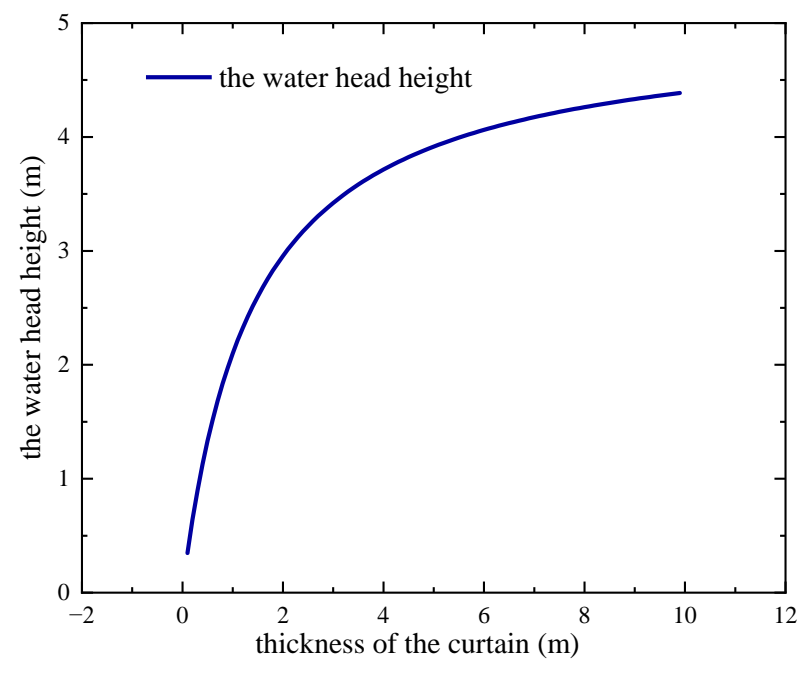

(b) influence of curtain's thickness on water pressure

Figure 17. The effect of the thickness of horizontal curtain on water inflow.

\subsubsection{Curtain Position}

Put all parameters into Equation (15), and the calculation results of water inflow with different positions of horizontal curtain can be obtained. The relative position relationship between the horizontal curtain and the sandy loam soil layer is shown in Figure 18, and the calculation results of water pressure and water inflow are shown in Figure 19.

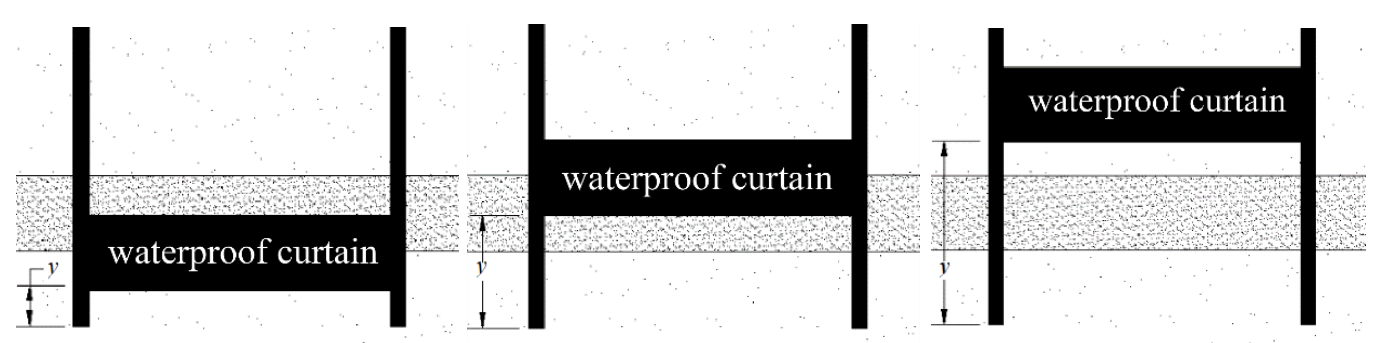
(a) The curtain is under the sandy loam soil layer
(b) The curtain is over the sandy loam soil layer
(c) The curtain is over the sandy loam soil layer (Some distance apart)

Figure 18. Position sketch of both horizontal curtain and impermeable layer. ( $y$ the distance between the curtain's bottom and the diaphragm wall's bottom).

For the stage (1) in Figure 19a, $0 \mathrm{~m}<z \leq 5 \mathrm{~m}$, the horizontal curtain is below and overlaps the weak permeable layer. The water pressure diagram shows that the water head height at this stage is about $4.4 \mathrm{~m}$, which is close to the initial water level. This situation occurs because $\beta$ is very small, and the coarse sand layer contributes little to the head loss of seepage. The variation diagram shows that the head height decreases slowly with the distance, and the falling speed is in the middle of three stages. There are two reasons for this phenomenon. One is that when the horizontal curtain rises, the distance of water flow to the bottom of the curtain increases and the head loss increases along the way. The second is that as the horizontal curtain rises, its overlap with the weak permeable layer increases, resulting in a decrease of the thickness of the weak permeable layer. As a result, 
the effective water-blocking layer thickness in the whole seepage path is reduced, but the total hydraulic slope is unchanged, so the water head height at the bottom of the horizontal curtain will be reduced. The figure of water inflow variation shows that the water inflow per unit length of foundation pit is $0.11-0.12 \mathrm{~m}^{3} / \mathrm{d}$ at the stage (1) in Figure $19 \mathrm{~b}$, indicating that the horizontal curtain has a pronounced water-blocking effect. With the rise of the horizontal curtain, the water inflow of the foundation pit gradually increases. The reason is that the rise of the horizontal curtain leads to the decrease of the thickness of the weak permeable layer and the decrease of the effective water resistance thickness in the total seepage path, which leads to the increase of the water inflow in the foundation pit.

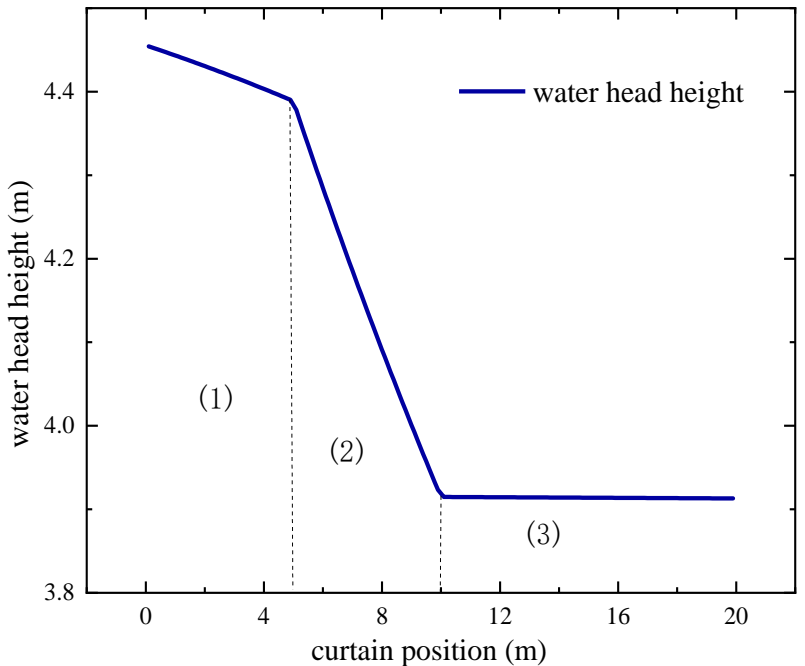

(a) influence of curtain's position on water pressure

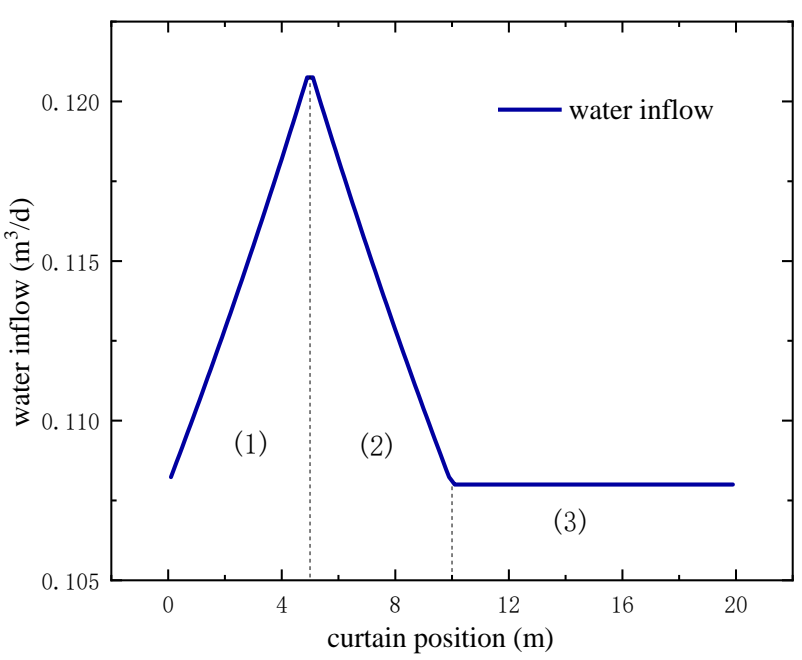

(b) influence of curtain's position on water inflow

Figure 19. The effect of curtain position on result diagram.

For the stage (2) in Figure 19a, $5 \mathrm{~m}<z \leq 10 \mathrm{~m}$, the horizontal curtain is above and overlaps the weak permeable layer. The variation diagram of water pressure shows that the head height drops rapidly with the distance, and the rate of decline is the first of the three stages. The reason is that the horizontal curtain rises and the thickness of the weak permeable layer increases gradually. Moreover, the seepage first passes through the weak permeable layer before reaching the horizontal curtain. The weak permeable layer contributes a lot to the seepage head loss, and the head height of the fluid decreases significantly after passing through the weak permeable layer. Stage (2) in Figure 19b with the rise of the horizontal curtain, the water inflow of foundation pit is gradually decreasing. The reason is that the rise of the horizontal curtain leads to the increase of the thickness of the weak permeable layer and the increase of the effective water-resistance thickness in the total seepage path, which leads to the decrease of the water inflow in the foundation pit.

For the stage (3) in Figure 19a, $10 \mathrm{~m}<z \leq 20 \mathrm{~m}$, the horizontal curtain is above the weak permeable layer and separated from the weak permeable layer. The head height variation diagram shows that the head height at this stage is unchanged. The reason is that with the rise of the horizontal curtain, the thickness of the weak pervious layer does not change, and the seepage path to the bottom of the horizontal curtain only increases the distance of some coarse sand. The contribution of the coarse sand layer to the water head loss is very small, so adding a section of the coarse sand layer to the water head height at the bottom of the curtain can be ignored. Stage (3) in Figure 19b: With the rise of the horizontal curtain, the water inflow of foundation pit remains unchanged. The reason is that with the rise of the horizontal curtain, the length of soil with different hydraulic conductivities in the total seepage path does not change, and the total hydraulic slope is unchanged, so the water inflow of the foundation pit does not change. 
The above calculation results and analyses show that the head height at the bottom of the curtain drops as the horizontal curtain rises. The water inflow of the foundation pit rises firstly and then drops. Based on this, we can get the following enlightenment: In engineering practice, it is preferred to set the horizontal curtain above the weak permeable layer, where the water head height at the curtain bottom and the water discharge of foundation pit are both small. Secondly, it is considered that the horizontal curtain is set below the weak permeable layer. Although the water head height at the bottom of the curtain is relatively high, it is easy to ensure the stability at the bottom of the curtain because of the thick soil covering the top of the curtain. Moreover, the water inflow of the foundation pit is still very small. If neither of them could meet the construction conditions, the horizontal curtain can be set in the lower permeable layer. In this scheme, the water head height at the bottom of the horizontal curtain is moderate, but the water discharge in the foundation pit is the largest one. Therefore, the weak permeable layer below the foundation pit should be retained as far as possible during the construction of the horizontal closing curtain. A lower permeable layer is a natural barrier to control the water inflow of foundation pit.

\section{Application}

6.1. Case Study

Juyuanzhou Station of Fuzhou Metro Line 2 is located in Cangshan District, Fuzhou City, China. The entire station is situated on Nantai Island, and its geographic location is shown in Figure 20. The station is located at the intersection of Jinxiang Road and Binzhou Road, along the east-west direction of Jinxiang Road. Figure 21 shows the surrounding environment and layout of the station. There is an urban inland river about $3 \mathrm{~m}$ to the north of the site, the water surface is about $10 \mathrm{~m}$ wide, and the water surface elevation is about 3.5 4.0 $\mathrm{m}$ (close to the groundwater level of the proposed site). There is a hydraulic connection between the inland river and the Min River, and the water level changes are related to the rise and fall of the Min River and the control of the river sluices. Due to the lining of the river, the hydraulic connection between river water and groundwater is weak, but in the case of broken lining, the river water will recharge the groundwater.

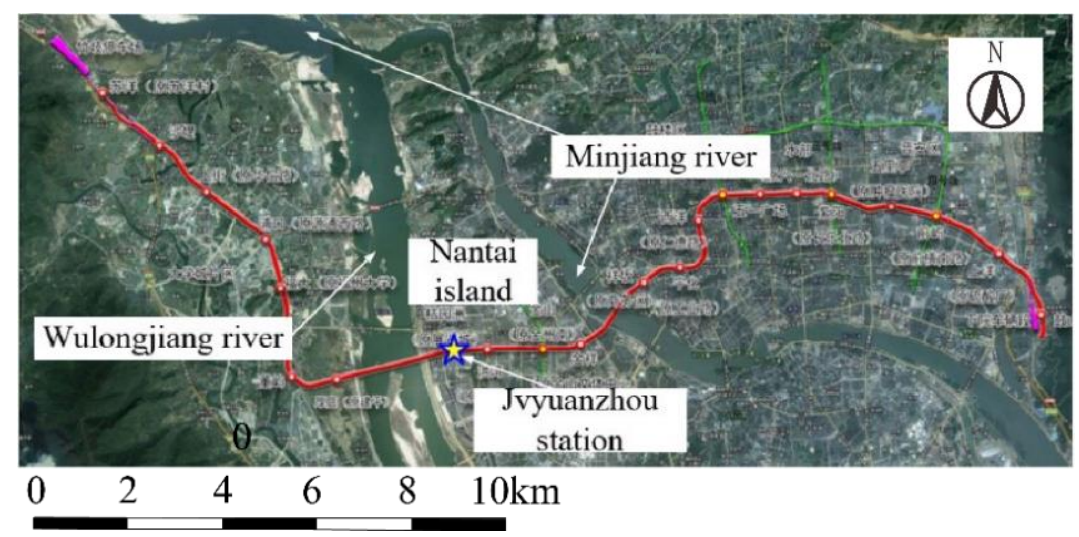

Figure 20. Station location.

The rock and soil layers of the station site are as follows from top to bottom: miscellaneous fill, coarse medium sand (slightly density), coarse medium sand (medium density), medium coarse sand, silty sand, silt with sand and gravel layers, as shown in Figure 22. The buried depth of the phreatic water level is $2.30 \sim 4.30 \mathrm{~m}$, and the aquifers are mainly coarse medium sand layer, silt fine sand layer, medium coarse sand layer and gravel layer. The aquifer mainly receives lateral runoff and leakage recharge. The specific parameters of each layer are shown in Table 5. 


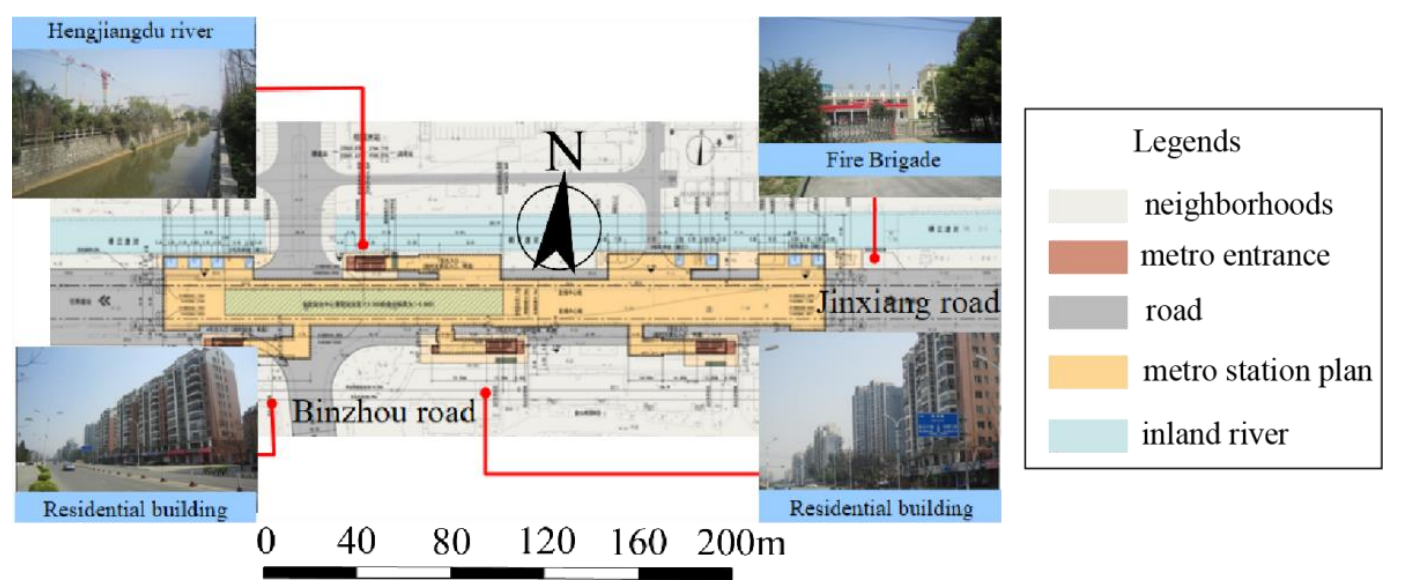

Figure 21. Station plan and surrounding environment.

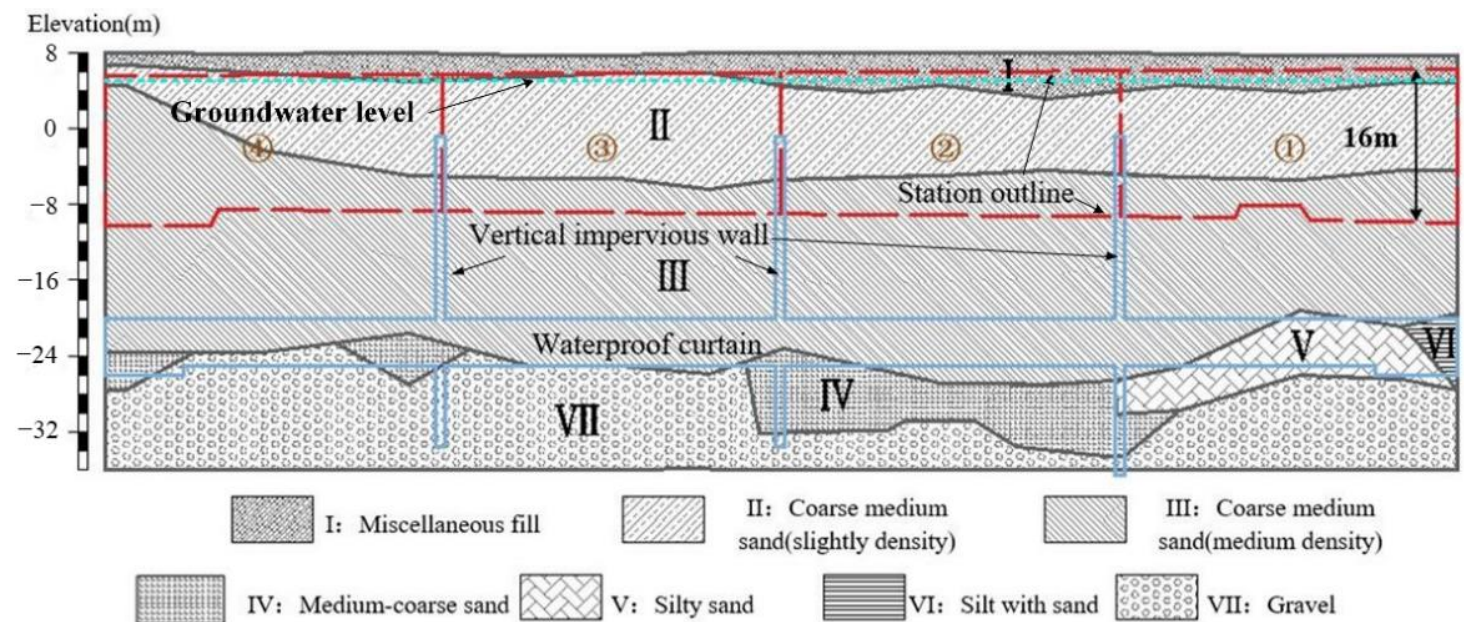

Figure 22. The diagram of the geological section and partition of the cut-off wall.

Table 5. Properties of the soil at the site.

\begin{tabular}{ccccccc}
\hline Name & $\gamma$ & $\mathbf{T}$ & $\mathbf{e}$ & $\mathbf{c}$ & $\boldsymbol{\rho}$ & $\mathbf{k}$ \\
\hline $\begin{array}{c}\text { I: miscellaneous fill } \\
\text { II: coarse medium sand } \\
\quad \text { (slightly density) }\end{array}$ & 18.5 & $1.2-3$ & - & 4 & 18 & - \\
III: coarse medium sand & 18.5 & $2.1-9$ & 0.81 & 4 & 20 & 42 \\
$\quad$ (medium density) & 19.0 & $16-28.2$ & 0.72 & 4 & 25 & 40 \\
IV: medium coarse sand & 19.5 & $0-4$ & 0.7 & 4 & 28 & 35 \\
$\quad$ V: silty sand & 18.5 & $0-6$ & 0.69 & 4 & 25 & 10 \\
VI: silt with sand & 17.0 & $1.2-3$ & 1.2 & 12 & 5 & 0.3 \\
$\quad$ VII: gravel & 21.0 & 7.5 -bottom & - & 2 & 35 & 55 \\
\hline
\end{tabular}

$\gamma$ natural unit weight $\left(\mathrm{kn} / \mathrm{m}^{3}\right) ; T$ thickness of the layer $(\mathrm{m}) ; e$ void ratio; $c$ cohesion $(\mathrm{kpa}) ; \varphi$ internal friction angle $\left({ }^{\circ}\right) ; k$ hydraulic conductivity $(\mathrm{m} / \mathrm{d})$.

Juyuanzhou Station has a total length of $285 \mathrm{~m}$ and a standard section width of $19.7 \mathrm{~m}$. It is an underground two-story island station. The depth of the foundation pit in the standard section is about $16 \mathrm{~m}$, and the open-cut method is used for construction. The main enclosure structure adopts a continuous wall with a thickness of $800 \mathrm{~mm}$, and the depth of the enclosure wall is about $38 \mathrm{~m}$. The cross-section of the station is shown in Figure 23 where the thickness of the soil layer can be easily found. 


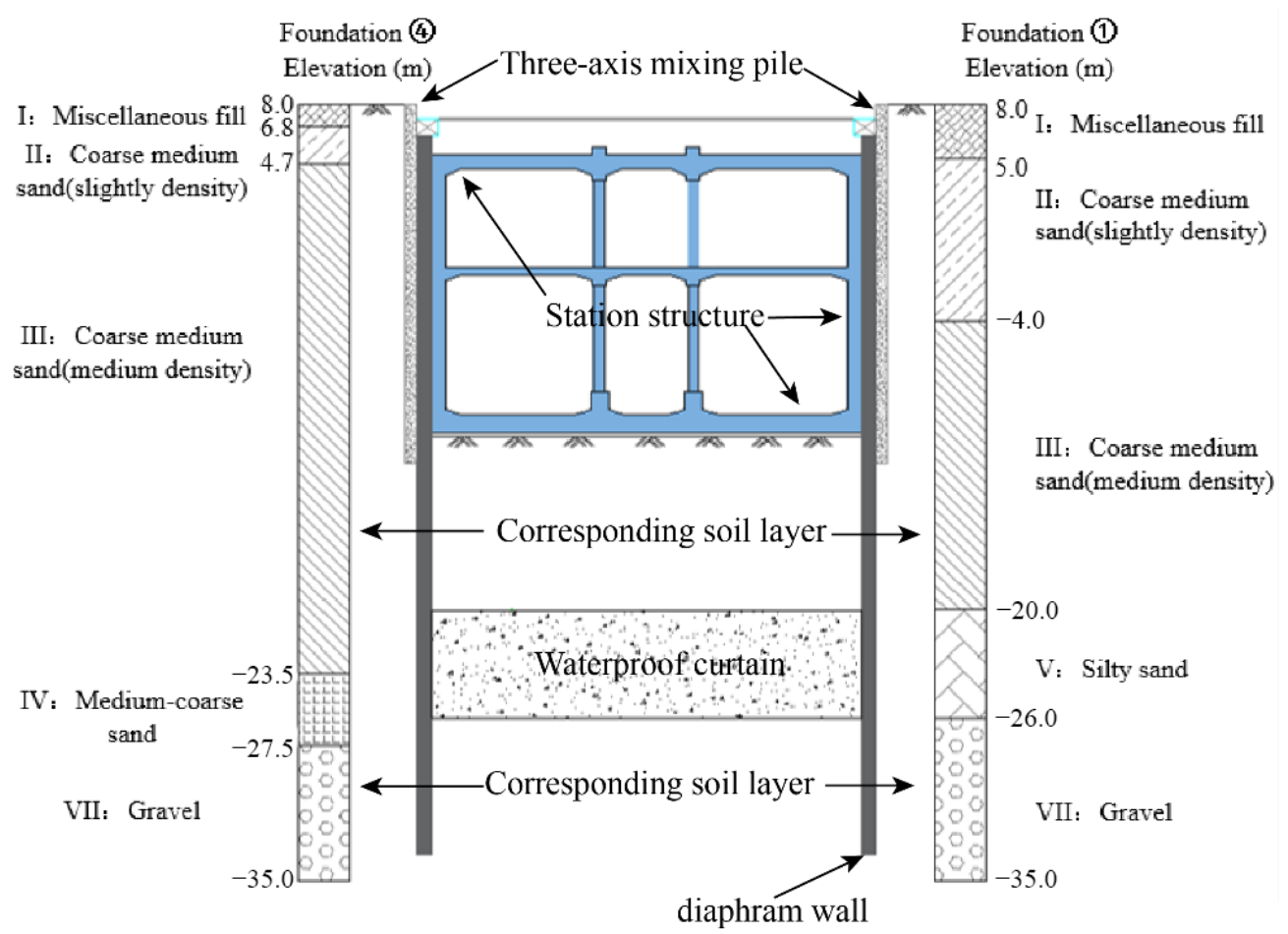

Figure 23. The cross section of the station.

\subsection{Design of Horizontal Waterproof Curtain}

As shown in Figure 23 and Table 5, the stratum of the foundation pit is a highly permeable stratum, which adds great difficulty to the design of the precipitation scheme. So the partial penetrating curtain can't meet the requirements of foundation pit dewatering. Besides, the full penetrating curtain is not suitable for this foundation pit scheme because of the high cost and difficult construction. To reduce the impact on the surrounding environment and meet the precipitation requirements, horizontal bottom curtains were employed in the station foundation pit. Moreover, three vertical curtain were constructed using triple-pipe jet grouting piles to reduce construction risks. This measure divides the foundation pit into four small foundation pits, among which the top elevation of the vertical partition wall is $-0.8 \mathrm{~m}$, and the schematic diagram of the foundation pit partition is shown in Figure 22.

According to the requirements of the design documents, the water inflow of each small foundation pit should be controlled within $15,000 \mathrm{~m}^{3} / \mathrm{d}$. As shown by the previous experiments, the water inflow calculation method proposed in this paper is smaller than the experimental data, and the relative error is within $25 \%$. Taking into account the uneven geological conditions and the strong water permeability of the stratum in actual construction, the safety factor of this method is 2.5 , that is, the water influx of $6000 \mathrm{~m}^{3} / \mathrm{d}$ is used as the control standard in this method. As shown by the geological map and the crosssectional view of the foundation pit, the water permeability of the geological environment of No. 4 foundation pit is higher than that of the others. Therefore, the standard section of the No. 4 foundation pit is used as an example to design the entire foundation pit, which can ensure the safety of precipitation measures. By substituting the parameters of the No. 4 foundation pit in the Table 5 and Figure 23 into the Equation (15), the water inflow and pressure under different permeability coefficients and heights can be obtained, and the structural safety can be checked by this.

It can be seen from Figure 24 that when the water inflow control standard is $6000 \mathrm{~m}^{3} / \mathrm{d}$, the curtain hydraulic conductivities corresponding to curtain thicknesses of $4,5,6$, and $7 \mathrm{~m}$ are $1.86,2.32,2.76,3.3 \mathrm{~m} / \mathrm{d}$, respectively. In the highly permeable stratum, the curtain is prone to bad quality, and it is difficult to guarantee the construction quality. The 
$4 \mathrm{~m}$-thick horizontal curtain has a high construction risk, so this scheme is not adopted. When the curtain thickness is $5 \mathrm{~m}$, the hydraulic conductivity is required to be lower than $2.32 \mathrm{~m} / \mathrm{d}$, which is easier to meet the requirements. The $5 \mathrm{~m}$ thick curtain can meet the waterproof requirements of the foundation pit, while the $6.7 \mathrm{~m}$ curtain is expensive, so it is not considered to be used in the standard section. The shield shaft section has a deeper foundation pit and stricter requirements for precipitation. Therefore, a $7 \mathrm{~m}$ thick horizontal curtain is used to improve its safety. The stability of the foundation pit and the anti-surge calculation are carried out through Figure 25, and the results show that the precipitation measure is safe. From the previous discuss, we know that the horizontal curtain position has the least influence on the water stop. However, it is not easy to pass the anti-floating calculation when the location is too shallow, and the construction quality of the pebble layer is difficult to guarantee when it is too deep. After comprehensive consideration, it is proposed that the elevation of the top of the horizontal curtain is $-20 \mathrm{~m}$.

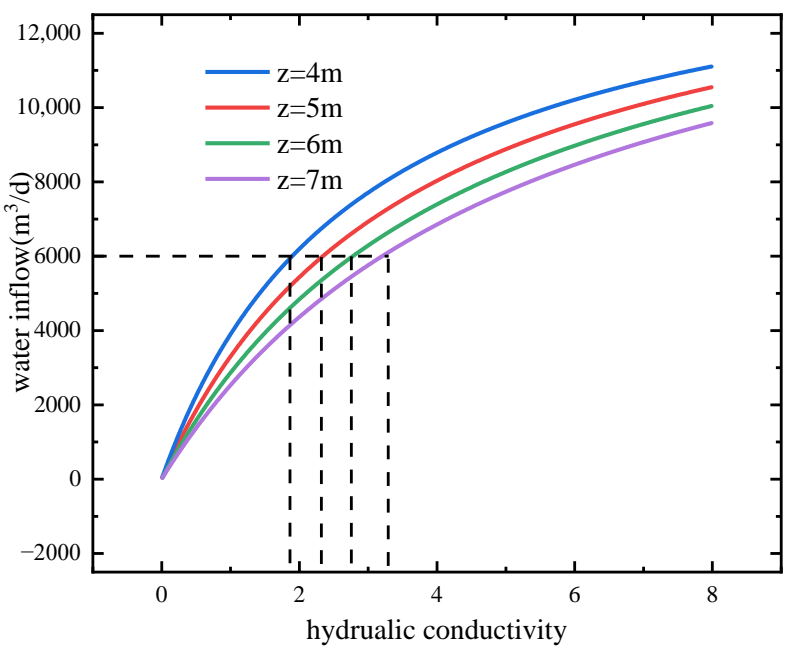

Figure 24. Change graph of water inflow with hydraulic conductivity.

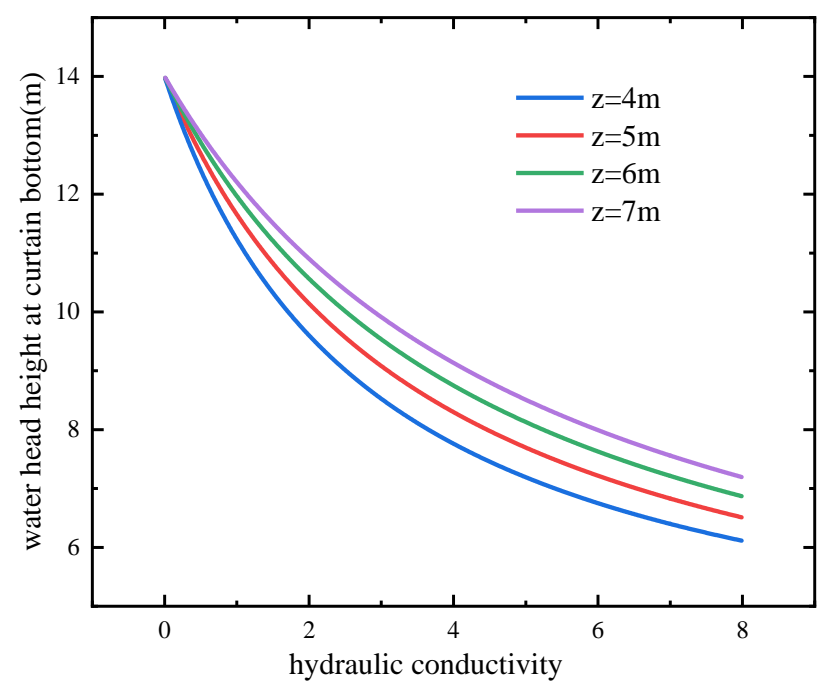

Figure 25. Change graph of water pressure with hydraulic conductivity.

Finally, the following design parameters are adopted: ultra-high pressure triple-tube jet grouting piles with a diameter of $1100 \mathrm{~mm}$ and a spacing of $850 \mathrm{~mm}$ are used for deep horizontal curtain, and the height of the top horizontal curtain is $-20 \mathrm{~m}$. The curtain hydraulic conductivity should be lower than $2.32 \mathrm{~m} / \mathrm{d}$, the curtain thickness of the standard section is $5 \mathrm{~m}$, and the curtain thickness of the end shield well section is $7 \mathrm{~m}$. It has been verified that the solution meets the requirements of stability and anti-floatation. 


\subsection{Dewatering Experiment \\ 6.3.1. Dewatering Scheme}

In order to ensure the safety of construction, carry out the foundation pit precipitation experiment. First, 34 dewatering wells (JS01-JS34) were arranged to carry out dewatering tests for each small foundation pit. Because of the disturbance to the upper soil during the construction of the jet grouting pile, the water output of a single well could not meet the design requirements. Later, ten pumping and observation wells (GB01-GB10) were added. In order to observe the change of water depth outside the foundation pit, 16 observation wells (SW01-SW16) were arranged for observation. The layout of the entire dewatering well and observation well is shown in Figure 26.

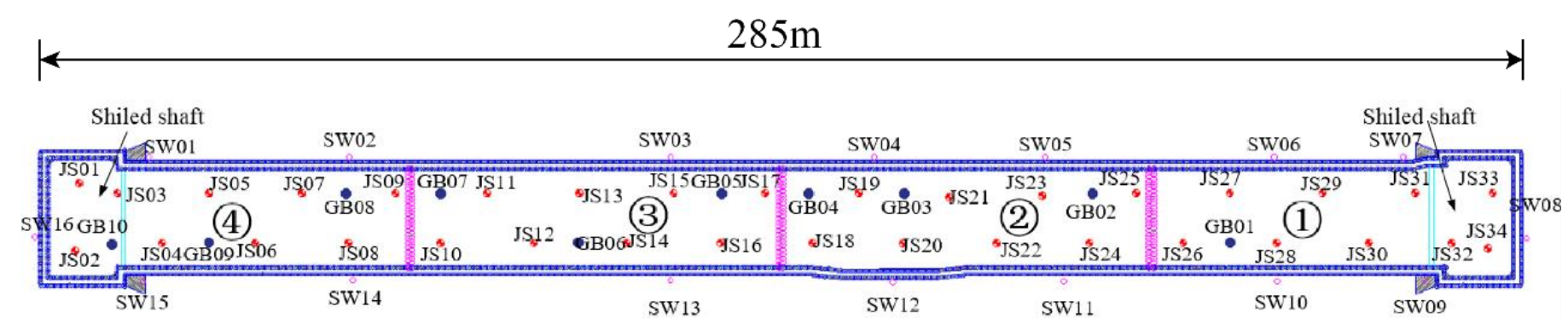

Figure 26. Pumping and observation wells distribution. (JS pumping wells; SW observation wells; GB pumping and observation wells).

\subsubsection{Dewatering of No.1 Pit}

A total of 6 pumping wells (JS29, JS28, JS26, JS31, JS32, JS33) were used for the dewatering test of No. 1 foundation pit. Three observation wells are set up to observe the water level drop. The observation well inside the pit is JS30, and the observation wells outside the pit are SW06 and JS25. The elevation of the top of the anti-seepage wall of the foundation pit partition is $-0.8 \mathrm{~m}$, which is lower than the groundwater level. If only the No. 1 foundation pit is dewatered, the water from the No. 2 foundation pit that is higher than the cut-off wall will flood into the No. 1 foundation pit, which will have a certain impact on the experimental results. In order to avoid the occurrence of the above-mentioned disadvantages, when the No. 1 foundation pit is pumped, the No. 2 foundation pit is also pumped. The observation pipe JS25 close to the cut-off wall ensures that the water from the No. 2 foundation pit will not flow into the No. 1 foundation pit. The time history curve of water level drop and water inflow in No. 1 foundation pit is shown in Figure 27. Since the JS34 foundation pit was blocked due to the construction, there was no observational data until the third day after precipitation.

It can be seen from the Figure 27 that the water level of JS25 is controlled to a depth of less than $10 \mathrm{~m}$ after pumping for one day, which eliminates the impact of the water in the No. 2 foundation pit on the No. 1 foundation pit. After precipitation, the water level of the standard section of the No. 1 foundation pit was buried at a depth of $18 \mathrm{~m}$, and the water level at the shield well was maintained at a buried depth of $22 \mathrm{~m}$, which met the excavation requirements. It can be seen from SW06 and SW10 that the water level outside the pit is maintained at a buried depth of $4 \mathrm{~m}$, indicating that the precipitation process has no impact on the surrounding environment and the water stop performance is very good. In the end, the water inflow of the foundation pit stabilized at $25-26 \mathrm{~m}^{3} / \mathrm{h}$, which was far less than the design control requirements, indicating that the water stop measures for the No. 1 foundation pit were successful. 


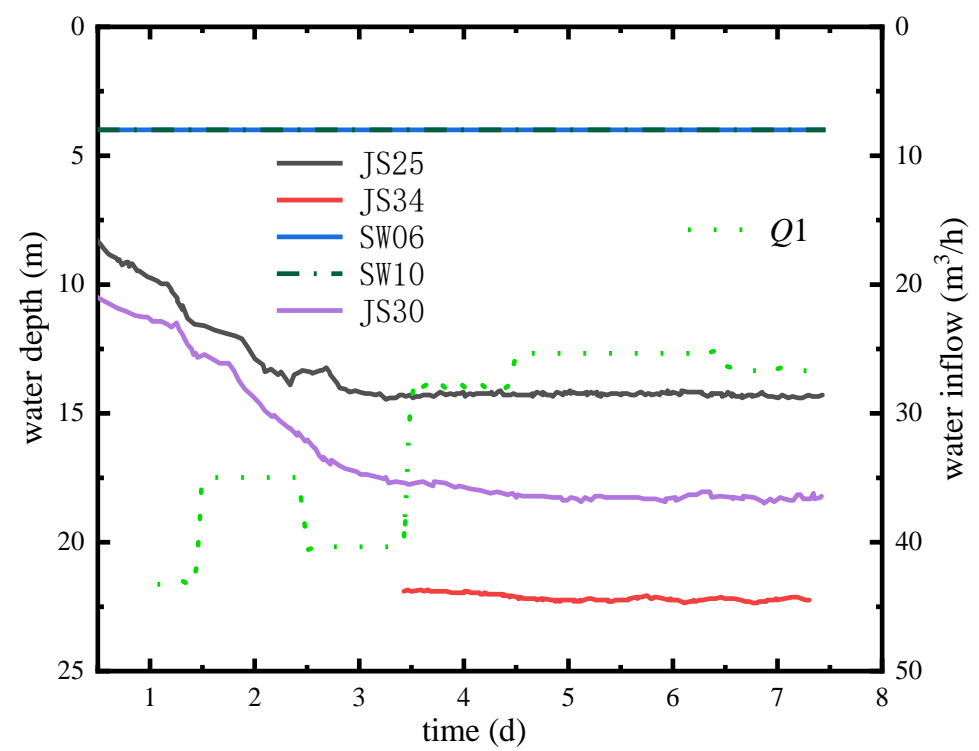

Figure 27. Water depth and water inflow in No.1 pit. (JS pumping wells; SW observation wells; $Q 1$ the water inflow inside the No. 1 pit).

\subsection{Result Analysis}

Facts have proved that although the horizontal curtain reduces the water inflow of the foundation pit, the horizontal curtain definitely has a certain permeability, which is consistent with the hypothesis of this article. In the engineering example, the area of the horizontal waterproof curtain of the No. 1 foundation pit is about $1412 \mathrm{~m}^{2}$. When the dewatering water level is stable, the water inflow of No. 1 foundation pit is $513 \mathrm{~m}^{3} / \mathrm{d}$, that is, the water inflow per unit area is $0.36 \mathrm{~m}^{3} / \mathrm{d}$, which is far less than the design requirement of $4 \mathrm{~m}^{3} / \mathrm{d}$. This implies that the performance of the horizontal waterproof curtain applied for the excavation case is good, which meets the requirements of design and safety.

\section{Conclusions}

(1) The theoretical calculation models of phreatic and confined water are established. Based on Darcy's seepage theory and flow balance principle, the calculation method of foundation pit water inflow and pressure with the horizontal waterproof curtain in strong permeable formation is derived.

(2) Indoor test models of the foundation pit with horizontal waterproof curtain are adopted. Comparing the test results with the calculated results, it is found that the relative error is about $20 \%$, and the reasons for the error are analyzed.

(3) The derived theoretical calculation methods are used to analyze the influence law of the hydraulic conductivity ratio, thickness and position of the horizontal waterproof curtain on the foundation pit seepage. It is found that the hydraulic conductivity ratio of the horizontal waterproof curtain has the most significant influence on the foundation pit. The thickness of the curtain has a certain effect on the water inflow in the foundation pit, but it has a limited effect on the water pressure at the bottom of the curtain. The curtain position has little effect on water inflow and pressure.

(4) Combined with the engineering example, various parameters of the curtain were designed according to the method in this paper. Subsequently, the water stopping effect of the horizontal curtain was analyzed by pumping test. The test results show that the design method is reliable and meets the requirements of foundation pit precipitation. 
Author Contributions: Conceptualization, C.S.; methodology, X.S. and C.C.; validation, L.L. and C.C.; formal analysis, M.L.; investigation, S.L.; resources, S.L.; writing—original draft preparation, C.S. and C.C.; writing-review and editing, X.S. All authors have read and agreed to the published version of the manuscript.

Funding: This research was funded by [General Program of National Natural Science Foundation of China] grant number [51778636].

Institutional Review Board Statement: Not applicable.

Informed Consent Statement: Informed consent was obtained from all subjects involved in the study.

Data Availability Statement: Some or all data: models, or code that support the findings of this study are available from the corresponding author upon reasonable request.

Conflicts of Interest: The authors declare no conflict of interest.

\section{References}

1. Xu, Y.-S.; Shen, J.S.; Zhou, A.-N.; Arulrajah, A. Geological and hydrogeological environment with geohazards during underground construction in Hangzhou: A review. Arab. J. Geosci. 2018, 11. [CrossRef]

2. Wu, H.-N.; Shen, S.-L.; Yang, J. Identification of Tunnel Settlement Caused by Land Subsidence in Soft Deposit of Shanghai. J. Perform. Constr. Facil. 2017, 31. [CrossRef]

3. Wu, Y.-X.; Lyu, H.-M.; Han, J.; Shen, S.-L. Dewatering-Induced Building Settlement around a Deep Excavation in Soft Deposit in Tianjin, China. J. Geotech. Geoenviron. Eng. 2019, 145. [CrossRef]

4. Shen, S.-L.; Wu, Y.-X.; Xu, Y.-S.; Hino, T.; Wu, H.-N. Evaluation of hydraulic parameters from pumping tests in multi-aquifers with vertical leakage in Tianjin. Comput. Geotech. 2015, 68, 196-207. [CrossRef]

5. Cao, C.; Shi, C.; Liu, L.; Liu, J.; Ye, Y. Novel Excavation and Construction Method for a Deep Shaft Excavation in Ultrathick Aquifers. Adv. Civ. Eng. 2019, 2019. [CrossRef]

6. Shi, C.H.; Cao, C.Y.; Lei, M.F.; Peng, L.M.; Jing, J. Optimal design and dynamic control of construction dewatering with the consideration of dewatering process. KSCE J. Civ. Eng. 2016, 21, 1-9. [CrossRef]

7. Jurado, A.; De Gaspari, F.; Vilarrasa, V.; Bolster, D.; Sánchez-Vila, X.; Fernàndez-Garcia, D.; Tartakovsky, D.M. Probabilistic analysis of groundwater-related risks at subsurface excavation sites. Eng. Geol. 2012, 125, 35-44. [CrossRef]

8. Huang, Y.; Bao, Y.; Wang, Y. Analysis of geoenvironmental hazards in urban underground space development in Shanghai. Nat. Hazards 2015, 75, 2067-2079. [CrossRef]

9. Wu, Y.-X.; Lyu, H.-M.; Shen, J.S.; Arulrajah, A. Geological and hydrogeological environment in Tianjin with potential geohazards and groundwater control during excavation. Environ. Earth Sci. 2018, 77. [CrossRef]

10. Cashman, P.M. Control of groundwater by groundwater lowering. Proc. Inst. Civ. Eng. Geotech. Eng. 1997, 125, 1-8. [CrossRef]

11. Huang, F.; Lyu, J.; Wang, G. The settlement models of deep vacuum dewatering method. Adv. Civ. Eng. 2019, 2019. [CrossRef]

12. Shaqour, F.M.; Hasan, S.E. Groundwater control for construction purposes: A case study from Kuwait. Environ. Geol. 2008, 53, 1603-1612. [CrossRef]

13. Vu, V.T.; Yao, L.H.; Wei, Y.J. Laboratory investigation of axisymmetric single vacuum well point. J. Cent. South Univ. 2016, 23, 750-756. [CrossRef]

14. Attard, G.; Winiarski, T.; Rossier, Y.; Eisenlohr, L. Review: Impact of underground structures on the flow of urban groundwater. Hydrogeol. J. 2015, 24, 5-19. [CrossRef]

15. Vilarrasa, V.; Carrera, J.; Jurado, A.; Pujades, E.; Vázquez-Suné, E. A methodology for characterizing the hydraulic effectiveness of an annular low-permeability barrier. Eng. Geol. 2011, 120, 68-80. [CrossRef]

16. Zeng, C.-F.; Zheng, G.; Xue, X.-L.; Mei, G.-X. Combined recharge: A method to prevent ground settlement induced by redevelopment of recharge wells. J. Hydrol. 2019, 568, 1-11. [CrossRef]

17. Ni, J.C.; Cheng, W.C.; Ge, L. A case history of field pumping tests in a deep gravel formation in the Taipei Basin, Taiwan. Eng. Geol. 2011, 117, 17-28. [CrossRef]

18. Wang, J.; Feng, B.; Yu, H.; Guo, T.; Yang, G.; Tang, J. Numerical study of dewatering in a large deep foundation pit. Environ. Earth Sci. 2013, 69, 863-872. [CrossRef]

19. Wang, J.; Huang, T.; Sui, D. Erratum: A case study on stratified settlement and rebound characteristics due to dewatering in shanghai subway station (The Scientific World Journal). Sci. World J. 2013, 2013. [CrossRef]

20. Meng, C.J.; Xiong, D.S.; Zhao, H.S.; Zhang, Y.; Yu, T.X. Assessment of effect of dewatering of excavations on nearby piers of operating high-speed railways. Yantu Gongcheng Xuebao 2014, 36, 265-268. [CrossRef]

21. Li, Z.; Han, M.; Liu, L.; Li, Y.; Yan, S. Corner and partition wall effects on the settlement of a historical building near a supported subway excavation in soft soil. Comput. Geotech. 2020, 128. [CrossRef]

22. Wang, J.; Wu, Y.; Liu, X.; Yang, T.; Wang, H.; Zhu, Y. Areal subsidence under pumping well-curtain interaction in subway foundation pit dewatering: Conceptual model and numerical simulations. Environ. Earth Sci. 2016, 75. [CrossRef] 
23. Liu, L.; Lei, M.; Cao, C.; Shi, C. Dewatering Characteristics and Inflow Prediction of Deep Foundation Pits with Partial Penetrating Curtains in Sand and Gravel Strata. Water 2019, 11, 2182. [CrossRef]

24. Wang, J.; Feng, B.; Guo, T.; Wu, L.; Lou, R.; Zhou, Z. Using partial penetrating wells and curtains to lower the water level of confined aquifer of gravel. Eng. Geol. 2013, 161, 16-25. [CrossRef]

25. Wang, X.W.; Yang, T.L.; Xu, Y.S.; Shen, S.L. Evaluation of optimized depth of waterproof curtain to mitigate negative impacts during dewatering. J. Hydrol. 2019, 577. [CrossRef]

26. Cao, C.; Shi, C.; Liu, L.; Liu, J. Evaluation of the effectiveness of an alternative to control groundwater inflow during a deep excavation into confined aquifers. Environ. Earth Sci. 2020, 79, 1-13. [CrossRef]

27. Cao, C.; Shi, C.; Lei, M. A simplified approach to design jet-grouted bottom sealing barriers for deep excavations in deep aquifers. Appl. Sci. 2019, 9, 2307. [CrossRef]

28. Modoni, G.; Flora, A.; Lirer, S.; Ochmański, M.; Croce, P. Design of jet grouted excavation bottom plugs. J. Geotech. Geoenviron. Eng. 2016, 142. [CrossRef]

29. Liu, J. The application of land subsidence control technologies caused by deep foundation pit dewatering. Proc. IAHS 2020, 382, 775-780. [CrossRef]

30. Shen, S.L.; Wu, Y.X.; Misra, A. Calculation of head difference at two sides of a cut-off barrier during excavation dewatering. Comput. Geotech. 2017, 91, 192-202. [CrossRef]

31. Zhang, W.; Wang, W.; Zhou, D.; Zhang, R.; Goh, A.T.C.; Hou, Z. Influence of groundwater drawdown on excavation responses-A case history in Bukit Timah granitic residual soils. J. Rock Mech. Geotech. Eng. 2018, 10, 856-864. [CrossRef]

32. Wang, J.; Liu, X.; Liu, S.; Zhu, Y.; Pan, W.; Zhou, J. Physical model test of transparent soil on coupling effect of cut-off wall and pumping wells during foundation pit dewatering. Acta Geotech. 2019, 14, 141-162. [CrossRef]

33. Xu, Y.S.; Yan, X.X.; Shen, S.L.; Zhou, A.N. Experimental investigation on the blocking of groundwater seepage from a waterproof curtain during pumped dewatering in an excavation. Hydrogeol. J. 2019, 27, 2659-2672. [CrossRef]

34. Zhang, L.; Zhou, X.; Pan, Y.; Zeng, B.; Zhu, D.; Jiang, H. Design of Groundwater Extraction in Open Cut Foundation Pit and Simplified Calculation of Ground Subsidence due to Dewatering in Sandy Pebble Soil Strata. Adv. Civ. Eng. 2020, 2020. [CrossRef] 